NBER WORKING PAPER SERIES

\title{
REALLOCATION AND TECHNOLOGY: \\ EVIDENCE FROM THE U.S. STEEL INDUSTRY
}

\author{
Allan Collard-Wexler \\ Jan De Loecker \\ Working Paper 18739 \\ http://www.nber.org/papers/w18739
NATIONAL BUREAU OF ECONOMIC RESEARCH
1050 Massachusetts Avenue
Cambridge, MA 02138
January 2013

This project was funded by the Center for Economic Policy Studies (CEPS) at Princeton University and the Center for Global Economy and Business (CGEB) at New York University. We would like to thank Jun Wen for excellent research assistance, and Jonathan Fisher for conversations and help with Census Data. We would like to thank Rob Clark, Liran Einav, Ariel Pakes, Kathryn Shaw, Chad Syverson, Raluca Dragusanu, and seminar participants at many institutions. This paper uses restricted data that was analyzed at the U.S. Census Bureau Research Data Center in New York City. Any opinions and conclusions expressed herein are those of the authors and do not necessarily represent the views of the U.S. Census Bureau or the National Bureau of Economic Research. All results have been reviewed to ensure that no confidential information is disclosed.

NBER working papers are circulated for discussion and comment purposes. They have not been peerreviewed or been subject to the review by the NBER Board of Directors that accompanies official NBER publications.

(C) 2013 by Allan Collard-Wexler and Jan De Loecker. All rights reserved. Short sections of text, not to exceed two paragraphs, may be quoted without explicit permission provided that full credit, including (C) notice, is given to the source. 
Reallocation and Technology: Evidence from the U.S. Steel Industry Allan Collard-Wexler and Jan De Loecker

NBER Working Paper No. 18739

January 2013

JEL No. L1,O3

\begin{abstract}
$\underline{\text { ABSTRACT }}$
We measure the impact of a drastic new technology for producing steel - the minimill - on the aggregate productivity of U.S. steel producers, using unique plant-level data between 1963 and 2002. We find that the sharp increase in the industry's productivity is linked to this new technology, and operates through two distinct mechanisms. First, minimills displaced the older technology, called vertically integrated production, and this reallocation of output was responsible for a third of the increase in the industry's productivity. Second, increased competition, due to the expansion of minimills, drove a substantial reallocation process within the group of vertically integrated producers, driving a resurgence in their productivity, and consequently of the industry's productivity as a whole.
\end{abstract}

\author{
Allan Collard-Wexler \\ Stern School of Business \\ New York University \\ 44 West Fourth Street \\ KMC-7-80 \\ New York, NY 10012 \\ and NBER \\ wexler@nyu.edu \\ Jan De Loecker \\ Department of Economics \\ 307 Fisher Hall \\ Princeton University \\ Princeton, NJ 08544-1021 \\ and NBER \\ jdeloeck@princeton.edu
}




\title{
Reallocation and Technology: Evidence from the U.S. Steel Industry*
}

\author{
Allan Collard-Wexler and Jan De Loecker \\ NYU and NBER, and Princeton University, NBER and CEPR
}

First version February 2012, current version January 2013

\begin{abstract}
We measure the impact of a drastic new technology for producing steel - the minimill on the aggregate productivity of U.S. steel producers, using unique plant-level data between 1963 and 2002. We find that the sharp increase in the industry's productivity is linked to this new technology, and operates through two distinct mechanisms. First, minimills displaced the older technology, called vertically integrated production, and this reallocation of output was responsible for a third of the increase in the industry's productivity. Second, increased competition, due to the expansion of minimills, drove a substantial reallocation process within the group of vertically integrated producers, driving a resurgence in their productivity, and consequently of the industry's productivity as a whole.
\end{abstract}

\section{Introduction}

Identifying the sources of productivity growth of firms, industries, and countries, has been a central question for economic research. There remain, however, many empirical obstacles to credibly identify the underlying sources of productivity growth. First, the measurement of productivity at the producer level typically requires an estimate of the production function and, therefore, has to confront both the endogeneity of inputs and unobserved prices for inputs and outputs. Second, it is difficult to observe potential explanatory variables at the producer level, such as technology, competition, and management practices $]^{1}$ Finally, in order to establish causality, exogenous shifters

\footnotetext{
${ }^{*}$ This project was funded by the Center for Economic Policy Studies (CEPS) at Princeton University and the Center for Global Economy and Business (CGEB) at New York University. We would like to thank Jun Wen for excellent research assistance, and Jonathan Fisher for conversations and help with Census Data. We would like to thank Rob Clark, Liran Einav, Ariel Pakes, Kathryn Shaw, Chad Syverson, Raluca Dragusanu, and seminar participants at many institutions. This paper uses restricted data that was analyzed at the U.S. Census Bureau Research Data Center in New York City. Any opinions and conclusions expressed herein are those of the authors and do not necessarily represent the views of the U.S. Census Bureau. All results have been reviewed to ensure that no confidential information is disclosed.

${ }^{1}$ See Syverson (2011) for an excellent overview of the various potential determinants of productivity at both the producer and industry level. Two prominent studies on the triggers of productivity growth are Schmitz (2005) and Olley and Pakes (1996), who study the role of two such triggers: import competition in the iron ore market and deregulation in the telecommunications market. Hortaçsu and Syverson (2004), Bloom, Eifert, Mahajan, McKenzie, and Roberts (2011), and Jarmin, Klimek, and Miranda (2009) show that factors such as vertical integration, management, and large retail chains lead to systematic differences in productivity between plants and consequently, have implications for aggregate industry performance.
} 
of such variables are required in order to trace out their effects on productivity.

In this paper, we shed light on the role of a specific driver: the arrival of a new technology. We evaluate the impact of a drastic technological change on aggregate productivity growth, while at the same time controlling for potentially additional drivers of productivity growth such as international competition, geography, and firm-level factors such as organization and management.

A recent literature has emphasized the distinction between the productivity effects that occur at the producer level, and those realized by moving resources between producers - i.e., the reallocation mechanism. Although it is well established, by now, at both a theoretical and empirical level that the reallocation of resources across producers is important in explaining aggregate outcomes, it has been very hard to identify the exact mechanisms behind it.2 In this paper, we focus on the role of technology and associated changes in competition in driving reallocation.

We examine one particular industry, the U.S. steel sector, for which we have detailed producerlevel production and price data. Our setting is well suited to measuring the role of technological change, since we directly observe the exogenous arrival of a new production process - the minimill - at the plant level. In addition, we observe detailed output and input data, including physical measures of inputs and outputs, as well as standard revenue and expenditure data, to obtain measures of productivity and market power. These inputs and outputs are remarkably unchanging over a forty year period, and the steel products shipped in the sixties are very similar to those shipped in 2000. Thus, productivity growth in steel is almost uniquely driven by process innovation, rather than through the introduction of new goods. The long panel, 1963-2002, of steel producers allows us to study the long-run implications of increased competition, such as the (slow) entry and exit process.

The U.S. steel industry shed about 75 percent of its workforce between 1962 to 2005, or about 400,000 employees. This dramatic fall in employment has far-reaching economic and social implications. For example, between 1950 to 2000, Pittsburg - which used to be the center of the U.S. Steel Industry - dropped from the 10th largest city in the United States to the 52nd largest.

While employment in the Steel Sector fell by a factor of five, shipments of steel products in 2005 reached the same level of the early sixties.Thus output per worker has grown by a factor of five, while total factor productivity (TFP) increased by 38 percent. Over the last three decades, this makes the steel sector one the fastest growing industries among large manufacturing industries, behind only the computer software and equipment industries. We highlight the special features of the U.S. steel industry in Table 1, where we report the change in output, employment and TFP over the period 1972-2002 for the U.S. steel sector and compare it to the mean and median manufacturing sector's experience.

Table 1 points out the unique feature of the steel industry: The period of impressive productivity growth, 28 percent compared to the median of 3 percent, occurred while the sector contracted by 35 percent. The starkest difference is the drop in employment of 80 percent compared to a decline

\footnotetext{
${ }^{2}$ For instance Melitz (2003), shows how trade liberalization impacts aggregate productivity through a reallocation towards more-productive firms, while Foster, Haltiwanger, and Krizan (2001) and Bartelsman, Haltiwanger, and Scarpetta (2009) document the role of reallocation empirically, using firm-level data.
} 
of 5 percent for the average sector.

We find that the main reason for the rapid productivity growth and the associated decline in employment is neither a steady drop in steel consumption, nor a consequence of globalization. Nor is it a displacement of production away from the midwest. The increase in productivity can be directly linked to the introduction of a new production technology, the steel minimill. The minimill displaced the older technology, called vertically integrated production, and this reallocation of output was responsible for about a third of the increase in the industry's total factor productivity. In addition, minimills' productivity steadily increased through a slow process of learning by doing. We directly attribute almost half of the aggregate productivity growth to the entry of this new technology.

However, the older technology was not entirely displaced. Instead, vertically integrated producers experienced a dramatic resurgence of productivity and, by 2002, are on average as productive as minimills. This resurgence was not driven by improvements at integrated plants. Instead, lessproductive vertically integrated plants were driven out of the industry, and output was reallocated to more-efficient producers. We find that the increased competition, due to the entry and expansion of minimills, was directly responsible for this reallocation process among incumbents.

In addition to identifying the exact mechanisms underlying productivity growth, which are of interest to a growing literature on reallocation and productivity dispersion, the steel industry is also important in and of itself. Even today, it is one of the largest sectors in U.S. manufacturing: In 2007, steel plants had shipments of over 100 billion dollars, of which half was value added. Therefore, understanding the sources of productivity growth in this industry is of independent interest.

The remainder of the paper is organized as follows. In Section 2, we discuss the rich plant-level data from the Census. In Section 3, we present five key facts that help guide the empirical analysis, which we take up in Section 4. We discuss alternative explanations in Section 5 and conclude in Section 6 .

\section{Data}

We study the production of steel: plants engaged in the production of either carbon or alloy steels. We rely on detailed Census micro data to investigate the mechanisms underlying the impressive productivity growth in the U.S. steel sector. Our analysis is based on plant-level production data of U.S. steel mills from 1963 to 2002.

We use data provided by the Center for Economics Studies at the United States Census Bureau. Our primary sources are the Census of Manufacturers (CMF), the Annual Survey of Manufacturers (ASM), and the Longitudinal Business Database (LBD). We select plants engaged in the production of steel, coded in either NAICS (North American Industrial Classification) code 33111, or SIC (Standard Industrial Classification) code 3312. The CMF is sent to all steel mills every five years, while the ASM is sent to about 50 percent of plants in non-Census years. However, the ASM 
samples all plants with over 250 employees and, encompasses over $90 \%$ of the output of the steel sector.

In addition, we collect data on the products produced at each plant using the product trailer to the CMF and the ASM, and, collect the materials consumed by these plants from the material trailer to the CMF.

We rely on our detailed micro data to break up steel mills into two technologies: Minimills (MM, hereafter) and Vertical Integrated (VI, hereafter) Producers. VI production takes place in two steps. The first stage takes place in a blast furnace, which combines coke, iron ore, and limestone to produce pig iron and slag. The pig iron, along with oxygen and fuel, is then used in a basic oxygen furnace (BOF) to produce steel ${ }^{3}$ The steel products produced in either MM or VI plants are shaped into sheets, bars, wire, and tube in rolling mills. These rolling mills are frequently collocated with steel mills, but can also be freestanding units.

In contrast, MMs are identified primarily by the use of an electric arc furnace (EAF) to melt down a combination of scrap steel and direct reduced iron. Because these mills have a far smaller efficient scale, they are, on average, an order of magnitude smaller than vertically integrated producers. Historically EAFs were used to produce lower-quality steels, such as those used to make steel bars, while virtually all steel sheet (needing higher-quality steel), was produced in BOFs. However, since the mid-1980s, innovation in the EAFs has enabled them to produce certain types of steel sheet products, as well 4

We classify plants into minimills, vertically integrated plants, and rolling mills using their response to a specific questionnaire on steel mills attached to the 1997, 2002, and 2007 CMF. For prior years, we use the material and products produced by each plant to identify MM and VI plants. More detail on the classification of plants can be found in the Data Appendix. Table A.3 shows summary statistics for the sample of MM and VI plants. The average VI plant had shipments of 647 million dollars, of which 47 percent is value added, while the average MM plant shipped 153 million dollars, of which 44 percent is value added.

\section{$3 \quad$ Key Facts in the U.S. steel sector 1963-2002}

In this section, we briefly go over some key facts of the U.S. steel sector. These facts will be important to keep in mind when we analyze the sources of productivity growth.

\subsection{Stagnant Shipments, Rising Productivity}

From Table 1, we know that the productivity growth in the U.S. steel sector was one of the fastest in manufacturing. To better understand this period of impressive productivity growth, we plot total output next to labor and capital use in Figure 1. An important observation is that the

\footnotetext{
${ }^{3}$ There were a few open-hearth furnaces in operation during the sample period. However, as of the late 1960s, open-hearth plants account for only a very small portion of output, and the last open-hearth plant closed in 1991. See Oster (1982) for more on the diffusion of BOF mills.

${ }^{4}$ EAFs have a long history in steel making. However, before the 1960s, they primarily produced specialty steels.
} 
period of productivity growth came about while the industry as a whole contracted severely: Steel producers sold about 60 billion dollars in 1960 and, reached 100 billion dollars in shipments by the early seventies. A decade later, only 40 billion dollars were shipped, or, put differently, the sector's shipments decreased by more than half.

Total employment, on the other hand, consistently decreased, even during the recovery of output in the late eighties and throughout the nineties. The employment panel of Figure 1 shows that total employment fell from 500,000 to 100,000 employees. This is one of the sharpest drops in employment experienced by any sector in the U.S. economy. By 2000, the steel industry employed a fifth of the number of workers that it did in 1960, while production of steel went from 130 million tons in 1960 to 110 million tons in 2000. This implies that output per worker increased from 260 to 1100 tons $5^{5}$ Total material use tracks output quite closely, while labor and capital fell continuously over the entire period, which suggests that TFP had to increase to offset the sharp drop in labor and capital. ${ }^{6}$

\subsection{A New Production Technology: Minimills}

The entry of minimills in steel production constituted a drastic change in the actual production process of steel products. A natural question to ask is whether MM are any different than the traditional VI steel producers. We rely on a descriptive OLS regression where we regress direct measurable characteristics on an indicator variable, whether a plant is a vertically integrated producer. We consider a log specification such that the coefficient on the technology dummy directly measures the percentage premium of VI plants.

Table A.2 lists the set of estimated coefficients, and confirms that vertically integrated producers are, on average, four times bigger, as measured by the large coefficients on shipments, value added, and inputs. For example, VI plants, on average, ship 144 percent more than MM. Moreover, VI producers generate about 20 percent more shipments per worker, which suggests that they are more productive. However, when we combine the coefficients on all three inputs (labor, materials and capital) with the shipment premium, we see that total factor productivity (TFP) of MM is at least as high as that of VI producers. We turn to a more precise comparison of TFP across technologies in Section 4.

In addition to the average premium over the entire sample, we report time-specific coefficients. Across all the various characteristics, the VI coefficient falls over time. Most notably, shipments per worker were 23-percent higher for VI plants in 1963, but by 2002, there was no significant difference between the two technologies in terms of labor productivity. This pattern suggests that, over time, VI and MM producers became more alike, although VI producers still produce on a larger scale.

The coefficients on wages of six percent, shown in the last row of Table A.2, confirms the wellknown fact that VI producers, on average, pay higher wages. This is likely due to the impact of

\footnotetext{
${ }^{5}$ Shipments of steel in tons are collected from various Iron and Steel Institute Annual Statistical Reports American Iron and Steel Institute, 2010).

${ }^{\circ}$ For this aggregate analysis, we rely on the NBER's five-factor TFP estimate. See Bartelsman, Becker, and Gray (2000) for more detail.
} 
unionization - minimill workers typically being non-unionized 7 It is interesting to note that the wage gap between the technologies closes over time.

An important difference between MM and VI producers is the set of products they manufacture. Figure 2 shows that in $1997 \mathrm{MMs}$ accounted for 59 percent and 68 percent of shipments of steel ingots and hot-rolled bar, but only 15 percent and 14 percent of hot and cold rolled sheet. MM typically produce lower quality steel products, which are generally thicker products, while VI plants produce higher quality products, which are usually sheet products. However, the product mix accounted for by MM changed dramatically over the last 40 years. Figure 2 shows that, in 1977, MMs produced 27 percent of steel ingots and 24 percent of hot-rolled bar. Between 1977 and 1982, MMs increased their share of these products to 40 percent, and by 2002, 81 percent of hot-rolled bar was produced by MMs. As stated above, in 1997, only 15 percent and 14 percent of hot and cold rolled sheet are produced by MMs 8 Thus, the market share of MM in the higher-quality product segments, sheet products, was rather stable up to 1997, after which their market shares did increase substantially.

\subsection{A Stable Product Mix over Time}

We list the product mix of the steel industry in Table A.3. We break down steel into various products: a) hot-rolled steel sheet (HRS) b) hot-rolled bar (HRB) c) cold-rolled sheet (CRS) d) ingots and shapes e) pipe and tube (P\&T) f) Wire g) cold-finished bars (CFB), and h) coke oven and blast furnace products (Blast). Over 40 years, the product mix for steel has barely changed. Hot-rolled sheet account for 23 percent of shipments in 1963 and 31 percent in 2002, and hot-rolled bar account for 23 percent of shipments in 1963 and 22 percent in 2002.

The fact that the steel industry's products have been unchanged is essential for our identification of productivity growth, as the industry's production process has changed far more than its products.

\subsection{Heterogeneous Price Trends Across Products}

While the product mix of steel producers has been relatively unchanged from 1963 to today, the prices for these products have dropped considerably, which is unsurprising given the large increases in TFP in the industry. Figure 6 presents the price indices for the four main products - hot and cold rolled sheet, hot rolled bar and steel ingots - which, taken together, represent 80 percent of shipments in $1997 \cdot 9^{9}$

Figure 6 shows that the prices of all steel products followed a very similar, and gradually increasing, pattern up to 1980. But from 1982 to 2000, there is a 50-percent drop in the real price

\footnotetext{
${ }^{7}$ See Hoerr $(1988)$ - and in particular, page 16 - for evidence of the role of unionization on wages for VI and MM producers.

Giarratani, Gruver, and Jackson 2007) discuss the entry of Minimills into the production of sheet products around 1990.

${ }^{9}$ We have taken care to deflate these price indices by the GDP deflator to show price trends for steel relative to the rest of the economy.
} 
of steel. This implies that, while shipments of steel in dollars dropped since 1980, the quantity shipped has gradually increased since the mid-eighties (see Panel 1 of Figure 1) 10

In addition, when we decompose these price trends further, we find that the prices of hot-rolled bars and steel ingots have fallen faster than the prices for hot and cold rolled sheet. While sheet steel is produced primarily by VI producers, prices for bar and ingot products fell by ten percent more than those for sheet products in 1982-1984. This occurred precisely at the point at which MM saw an increase of their market share of bar and ingot products.

In order to correctly identify the productivity effect of the arrival of the minimills, and their associated increased competition, it will therefore be imperative to control for price differences across plants and time.

\subsection{Simultaneous Entry and Exit}

From Figure 1, we know that the number of plants increased over time. In Table 2, we go a step further, and show both the number of MM and VI plants that entered or exited, and as well as the market share these plants represent. There was marked entry of new plants in the early eighties, a period during which the industry as a whole was severely contracted.

The market share of plants entering from 1982 to 1992 was 20 percent, versus five percent in the previous two decades, while the market share of exitors was 18 percent during this period. Most entry in this period was due to minimills, and most exit was from vertically integrated producers ${ }^{11}$ From these entry and exit statistics, we expect an important role for entry and exit in explaining productivity growth.

\section{Drivers of productivity growth}

The previous section highlighted the difference in performance between MM and VI producers, and suggests a large potential role for reallocation across these technologies in explaining productivity growth. This paper is concerned with studying the productivity differences in detail and verify the extent to which the entry of minimills contributed to the stark aggregate productivity growth in the industry, and we proceed in two steps.

First, we start by presenting our empirical framework. Second, we rely on our productivity estimates to verify the importance of reallocation, both across and within technology, in productivity growth. We consider both static and dynamic decompositions, which enables us to investigate the importance of entry and exit in productivity growth. Finally, we relate a direct measure of competition - markups - to the reallocation analysis by connecting markups to the analysis of reallocation, which relates market shares to productivity.

\footnotetext{
${ }^{10}$ Annual reports of the American Iron and Steel Institute (2010), where total tons of steel are recorded annually, indicate that quantity produced increased by about thirty percent between 1982 and 2002 .

${ }^{11}$ This phenomenon, the speeding up of exit and entry during a downturn, has been documented by Bresnahan and Raff (1991) in the motor vehicles industry during the Great Depression.
} 


\subsection{Productivity Differences Across Technology}

Denote each technology - either MM or VI - as $\psi \in\{V I, M M\}$ I2 $^{2}$ A plant $i$ at time $t$ can produce output $Q_{i j t}$ of a given product $j$, using a technology $\psi$ specific production technology:

$$
Q_{i j t}=F_{\psi, t}\left(L_{i j t}, M_{i j t}, K_{i j t}\right) \exp \left(\omega_{i t}\right)
$$

Our notation highlights that VI and MM producers rely on different technologies, which we allow to vary over time. As is common in the literature, productivity $\omega_{i t}$ is modeled as a Hicks-neutral term. Moreover, we assume that productivity is plant-specific.

\subsubsection{Measurement}

Recovering productivity using revenue and expenditure data requires that we correct for potential price variation across plants and time, for both output and inputs. Below, we describe our procedure briefly, and Appendix C provides more details.

In order to guarantee that we recover productivity, $\omega_{i t}$, using plant/product revenue data, we construct a plant-specific price $\left(P_{i t}\right)$. We assume that each product $j$ is homogeneous, and we directly observe each price $P_{j t}$ in the product-level BLS price data. Furthermore, we follow the literature and consider a Cobb-Douglas specification by type. We can, therefore, write equation (1) as:

$$
R_{i j t}=L_{i j t}^{\alpha_{l}} M_{i j t}^{\alpha_{m}} K_{i j t}^{\alpha_{k}} \exp \left(\omega_{i t}\right) P_{j t}
$$

Since we are interested in recovering a measure of productivity at the plant level, we aggregate product-level sales up to plant-level sales. A common restriction in these type of data is that we do not directly observe the input use by product (see Foster, Haltiwanger and Syverson 2008). We allocate inputs across products using product-specific sales shares, $s_{i j t}=\frac{R_{i j t}}{R_{i t}}$, such that $X_{i j t} \equiv$ $s_{i j t} X_{i t}$ with $X=\{L, M, K\} 13$ After aggregating (2) to the plant level we obtain:

$$
\frac{R_{i t}}{\sum_{j} s_{i j t} P_{j t}}=L_{i t}^{\alpha_{l}} M_{i t}^{\alpha_{m}} K_{i t}^{\alpha_{k}} \exp \left(\omega_{i t}\right)
$$

Although the focus in the literature has mostly been on the heterogeneity of output prices, input price variation potentially plagues the measurement of productivity as well. The data on intermediate input use, $M_{i t}$, are potentially the most contaminated by input price variation, both in the the time series, and in the cross-section, particularly between MM and VI plants. The two technologies use vastly different intermediate inputs, or use inputs at very different intensities

\footnotetext{
${ }^{12}$ Plants cannot change from one technology to another. In the steel industry, a plant never switches technology, such as becoming a minimill. This is in contrast to the a setting of technology adoption. See Van Biesebroeck (2003) for an empirical analysis of technology adoption in US car manufacturing.

${ }^{13}$ As discussed in detail in Appendix $\mathrm{C}$, this implies that we implicitly restrict markups to be common across products within a plant. We are not interested in explaining within-plant markup differences across products, but mainly aim to recover measures of plant-level productivity that are not contaminated by price variation across plants and time.
} 
and, therefore, we expect the relevant input price to vary substantially across plants of different technologies.

We construct our input price deflators in a similar way as the output price deflator. First, we need to distinguish between our three main input categories: labor, intermediate inputs and capital. We directly observe labor $L_{i t}$ : hours worked at the plant-level. For capital, we rely on the NBER capital deflator $\left(P_{t}^{k}\right)$ to correct the capital stock series.

We construct an intermediate input price index $P_{n t}$ for each intermediate input $n$, where $n=\{$ Fuels, Electricity, Coal for Coke, Iron Ore, and Scrap Steel $\}$, using either the NBER fuel price deflator, or reported quantities and costs in the material trailer to the CMF (which allow us to back out prices). We construct a plant-specific input price index $\left(P_{i t}^{M}\right)$ using a weighted average of these intermediate input specific prices, $P_{n t}$, where the shares are the share of an intermediate $n$ in total intermediate input use. Deflated intermediate input use is, thus, given by $M_{i t}=\sum_{n} \frac{M_{i n t}^{E}}{P_{i t}^{M}}$, where $M_{i n t}^{E}$ is the expenditure of plant $i$, at time $t$, on intermediate input $n$.

We present the time series pattern of our constructed input price index in Figure B.1. We compare the publicly available NBER Material Price Index (NBER MPI) with our constructed input price index. We compute the mean of the latter by technology and find that the NBER MPI follows our price index closely. However, the aggregate input price index hides the heterogeneity in input prices, in particular during the energy price spike in the late seventies and early eighties. This is particularly important given our focus on correctly identifying productivity differences across technology: We would overestimate the productivity premium for minimills. While input prices were very similar around 1972, by 1982, integrated producers faced almost 20-percent-higher input prices and this fact would artificially increase the productivity premium for minimills.

We estimate the production function using our constructed output and input price deflators using:

$$
\tilde{q}_{i t}=\beta_{l} l_{i t}+\beta_{m} m_{i t}+\beta_{k} k_{i t}+\omega_{i t}+\epsilon_{i t},
$$

where lower cases indicate logs of deflated variables when appropriate $\sqrt{14}$ We allow for unanticipated shocks to production and measurement error in output and prices, as captured by $\epsilon_{i t} t^{15}$ In the next section, we report the production function coefficients, and the corresponding minimill productivity premium, if any, under various specifications.

\subsubsection{Production function coefficients and technology premium}

We start by considering a few baseline specifications for the standard Cobb-Douglas production function. Table 3 presents estimates of the production function. Columns I, II and III show results with output defined as sales deflated by an aggregate price deflator, while Columns IV through

\footnotetext{
${ }^{14}$ E.g., $\tilde{q}_{i t}=\ln \left(\frac{R_{i t}}{\sum_{j} s_{i j t} P_{j t}}\right)$ and $m_{i t}=\ln \left(\sum_{n} \frac{M_{i n t}^{E}}{P_{n t}}\right)$.

${ }^{15}$ Formally the inclusion of $\epsilon_{i t}$ is compatible with the existence of measurement error and unanticipated shocks in both revenue and price data. E.g. we observe revenue in the data and it relates to a firm's measure as follows: $R_{i t}=R_{i t}^{*} \exp \left(\epsilon_{i t}\right)$. The error term $\epsilon_{i t}$ thus captures, potentially, multiple iid error terms. The distinction is not important for our analysis.
} 
IX show estimates using plant-level output and input deflators. Columns III, VI and IX present estimates using an investment control function approach as discussed in Ackerberg, Benkard, Berry, and Pakes (2007). We underscore that it is important in this context to explicitly allow the underlying demand and technology factors to vary with the technology type. More specifically, we index the investment policy function, the exit rule and the productivity process with the technology type indicator. Appendix C.1 provides more details on the estimation procedure. We compare our results to a few baseline OLS estimates, listed in the other columns, to highlight the importance of our corrections.

The production function coefficients, across all specifications, are stable and have reasonable estimates of returns to scale and output elasticities. An important test for our purpose is to check whether minimills and vertically integrated producers rely on different input factor shares. In order to test this, we simply interact every coefficient with our technology type dummy and run a $F$-test on the joint significance of the interacted coefficients. In doing so, we cannot reject that both technologies produce under the same output elasticities of labor, materials, and capital. At first, it might seem surprising that, for instance, the coefficient on materials does not vary across technologies. However, note that this coefficient reflects the importance of the total use of intermediate inputs in final production. Aggregating over the various intermediate inputs into $M_{i t}$ masks the distinct inputs used in production, which differ tremendously by technology 16

Four main results emerge from this analysis. First, minimills are, on average, more productive, as indicated by a negative coefficient on the VI dummy. Under specification I, minimills have a three-percent-higher TFP than vertically integrated producers, but this is not statistically significant. This result is surprising, both since industry participants believe that minimills are more productive, and since these plants show large increases in market share over the sample period.

Second, the TFP premium for minimills decreases over time as indicated by the positive coefficient of 0.3 percent on the technology-year. Although this coefficient is relatively small in magnitude, one has to keep in mind that our sample covers 40 years, which implies that by the end of our sample, the TFP premium for MM has disappeared. This will be important when we compute our decompositions - i.e., we expect the impact of minimills in aggregate productivity growth to be concentrated at the beginning of the sample.

Third, the results in Panel B demonstrate the importance of controlling for unobserved prices in the revenue-generating production function (Panel A) and confirm the findings of De Loecker (2011). In particular when we correct for plant-specific prices, we find that the minimill TFP premium is twice as high, and becomes significant. The impact of including detailed price data on the technology coefficient is as expected since we know from Figure 6 that VI plants are active in the relatively higher-quality segments, where producer prices are higher. Therefore, when we do not properly deflate the sales data, the productivity premium for minimills is dampened. The results in column IX indicate that correcting for differences in input prices across plants and time, in

\footnotetext{
${ }^{16}$ For instance, in 2002, Iron and Steel Scrap represented 42 percent of the coded material inputs for minimills, and Coal for the production of Coke represented 15 percent of the coded material inputs for vertically integrated plants.
} 
particular across technology, has the predicted effect: The magnitude of the minimill productivity premium is somewhat lower, 6.3 percent versus 11 percent, but it is still highly significant and substantial. The lower point estimate reflects the pattern of input prices in Figure B.1, that input prices for VI producers were higher in the late seventies and early eighties.

The impact of our price corrections are as expected. To illustrate our results, we find it useful to write out the potential bias induced by not deflating either output or inputs in light of our productivity analysis. We refer the reader to De Loecker (2011) and De Loecker, Goldberg, Khandelwal, and Pavcnik (2012) for more details on the impact of unobserved output and input prices, respectively. Using our production function, it is easy to show that, without deflating, the following equation is estimated on the data (in fact, Panel A considers such a specification):

$$
r_{i t}=\beta_{l} l_{i t}+\beta_{k} k_{i t}+\beta_{m} m_{i t}^{E}+\omega_{i t}+p_{i t}-\beta_{m} p_{i t}^{M}+\epsilon_{i t}
$$

This equation relates plant-level revenue $\left(r_{i t}\right)$ to (physical) labor, capital, and intermediate input use that potentially still contains input price variation $\left(m_{i t}^{E}\right)$. In addition to unobserved productivity, and a standard error term $(\epsilon)$, the production function also includes two price errors: (1) output price and (2) intermediate input price. Two observations are important to make. First, we will obtain biased production function coefficients since it is very likely that input use (both in physical terms and in expenditure terms for materials) is correlated with output and input prices. Second, the estimate for productivity is obtained using biased coefficients and will also include output and input price variation. We would not correctly identify the productivity difference between minimills and integrated plants without correcting for price variation, at both the input and output level.

Fourth, the selection and simultaneity biases understate the productivity advantages of minimills. Attenuation bias lowers the estimated returns to scale. Since VI plants are larger than minimills, this will make VI plants look more productive than they really are. Likewise, simultaneity typically results in downward bias on the capital coefficient. Since VI plants are more capital-intensive than minimills, this will again make VI plants appear more productive. When we correct for the simultaneity and selection biases in Columns III and VI, using an investment control function correction, the capital coefficient is twice as large. Moreover, the minimill TFP premium doubles to an average effect of 11 percent, starting at 25 percent in 1963 but disappearing by 2002 . In all the subsequent analysis, we rely on estimates of productivity, $\omega_{i t}$, from Column VI of Table 3. We also show all our main results using the various specifications discussed in Table 3 .

Technology does not explain all the differences in productivity, as the standard deviation of $\omega_{i t}$ is about 30 percent, while differences in technology account for an 11-percent gap in productivity. Thus, there remain substantial productivity differences between producers, both within and across technology types. This finding sits well with recent evidence on the dispersion of productivity across producers in narrowly defined industries. See Syverson (2011) for a recent survey. 


\subsection{The Role of Reallocation}

Following Olley and Pakes (1996), we consider industry-wide aggregate productivity as the market share, denoted by $s_{i t}$, weighted average of productivity $\omega_{i t}$. In particular, we rely on the following definition of aggregate productivity: $\Omega_{t} \equiv \sum_{i} s_{i t} \omega_{i t}$ which is different from the unweighted average of productivity $\bar{\omega}_{i t} \equiv \frac{1}{N_{t}} \sum_{i} \omega_{i t}$.

\subsubsection{Static Analysis: introducing a between-technology covariance}

In recent work, Bartelsman, Haltiwanger, and Scarpetta (2009) discuss the usefulness of the Olley and Pakes decomposition methodology. They highlight that the positive covariance between firm size and productivity is a robust prediction of recent models of producer-level heterogeneity (in productivity), such as Melitz (2003). We follow the standard decomposition of this aggregate productivity term (also referred to as the OP decomposition) into unweighted average productivity and the covariance between productivity and market share.

Definition Olley-Pakes Decomposition

$$
\Omega_{t}=\bar{\omega}_{t}+\sum_{i}\left(\omega_{i t}-\bar{\omega}_{t}\right)\left(s_{i t}-\bar{s}_{t}\right)=\bar{\omega}_{t}+\Gamma_{t}^{O P}
$$

where $\Gamma_{t}^{O P}$ is the Olley-Pakes Covariance.

The same decomposition can be applied by technology type $\psi$ - i.e., treating MM and VI producers as if they belong to separate industries - and this decomposition will help us understand whether average productivity of the different technology types evolved differently, and whether there is any substantial reallocation across producers of the same vintage. We call this the within decomposition. The market share of each technology is denoted $s(\psi)_{t}=\sum_{i \in \psi} s_{i t}$. Likewise, the type-specific aggregate productivity is $\Omega_{t}(\psi)$, while the average productivity within a technology type is $\bar{\omega}_{t}(\psi)$.

Definition Within-Technology Decomposition

$$
\begin{aligned}
\Omega_{t} & =\sum_{\psi \in M M, V I} s_{t}(\psi)\left(\bar{\omega}_{t}(\psi)+\sum_{i \in \psi}\left(\omega_{i t}-\bar{\omega}_{t}(\psi)\right)\left(s_{i t}(\psi)-\bar{s}_{t}(\psi)\right)\right) \\
& =\sum_{\psi \in M M, V I} s_{t}(\psi)\left(\bar{\omega}_{t}(\psi)+\Gamma_{t}^{O P}(\psi)\right) .
\end{aligned}
$$

This within decomposition reflects both the change in the actual type-specific component, the unweighted average and the covariance term, as well as the type-specific market share.

To measure the importance of reallocation of resources between technologies, we interact the productivity index with the type-specific market share, $s_{t}(\psi)$. We apply the same type of decomposition, but now the unit of observation is a type hence, one can think of two plants, an aggregate 
minimill and an aggregate vertically integrated producer. This allows us to isolate the betweentype reallocation component in aggregate productivity. Denote $\bar{\Omega}_{t}=\frac{1}{2} \sum_{\psi} \Omega(\psi)_{t}$ the industry productivity if minimills and vertically integrated producers had the same market share- i.e., the unweighted average, we obtain:

Definition Between Technology Decomposition

$$
\Omega_{t}=\bar{\Omega}_{t}+\sum_{\psi \in M M, V I}\left(s_{t}(\psi)-1 / 2\right)\left(\Omega_{t}(\psi)-\bar{\Omega}_{t}\right)=\bar{\Omega}_{t}+\Gamma_{t}^{B},
$$

where $\Gamma_{t}^{B}$ is the between Covariance measuring the extent to which the resource reallocation towards minimills contributed to the aggregate productivity for the entire industry. Notice that since the average market share is always one half, when the market share of minimills equals the market share of vertically integrated producers, the between covariance term $\Gamma_{t}^{B}$ is zero, regardless the productivity difference between the two types 17

Finally, we can group the within-technology and between-technology decomposition together to explain aggregate TFP:

$$
\Omega_{t}=\frac{1}{2} \sum_{\psi \in M M, V I}\left[\bar{\omega}_{t}(\psi)+\Gamma_{t}^{O P}(\psi)\right]+\Gamma_{t}^{B} .
$$

Notice that equation (9) allows us to explain changes in productivity, through i) changes in the average productivity of minimills and vertically integrated plants $\left(\bar{\omega}_{t}(\psi)\right)$; ii) changes in the covariance between output and productivity for both MM and VI plants $\left(\Gamma_{t}^{O P}(\psi)\right)$; or iii) reallocation across technologies $\left(\Gamma_{t}^{B}\right)$.

\subsubsection{Static reallocation analysis: results}

Table 4 shows the various cross-sectional decompositions of aggregate productivity - Olley-Pakes, Between, and Within - looking at their change from 1963 to 2002.

Three important results emerge. First, the Olley-Pakes decomposition of aggregate productivity across all plants shows, the average producer became 15.5 percent more-productive between 1963 and 2002. In addition, the reallocation towards more productive plants was an important process in generating higher productivity, generating a 7.5-percent increase from 1963 to 2002. Thus, aggregate productivity went up by 23 percent, of which one third was due to the reallocation towards more-productive plants. This indicates that reshuffling of market shares across producers was an important mechanism through which the industry realized productivity gains.

Second, we find a large role for the between-technology reallocation component $\left(\Gamma^{B}\right)$. In 1963 , the between covariance is -6.6 percent, as the older vintage of VI plants had both lower productivity and greater market share. The between covariance $\Gamma^{B}$ then became less negative as the minimills,

\footnotetext{
${ }^{17}$ Given the substantial entry of minimills that typically entered on a smaller scale, and remain smaller, we can expect the covariance term to be negative -i.e., the more-productive plants have a smaller market share. But we do expect this covariance term to become less negative over time, as Figure 2 shows that minimills started with a very small market share and gradually captured a larger part of the market.
} 
who have a productivity premium, gradually increased their market share. Towards the end of the sample period, minimills had about half of the market, which mechanically implies a zero between reallocation component. This between reallocation of output from VI plants to MMs accounts for a 6.3-percent increase in productivity, 27 percent of the overall productivity growth of the industry. The fact that the arrival of a new production technology can account for changes in the covariance term is critical since this suggests an important role for technology in explaining the reallocation that led to a sharp increase in productivity.

Third, drilling down to the technology type, we see that minimills increased their aggregate TFP $(\Omega(M M))$ by ten percent, while vertically integrated plants raised their aggregate TFP $(\Omega(V I))$ by 24 percent. This "catching-up" of vertically integrated producers mirrors the results in Table 3. While vertically integrated producers were less productive than the minimills, by the end of the sample period, they had almost completely caught up. Interestingly, the reason for this catch-up of vertically integrated producers is not due to changes in the Olley-Pakes covariance term $\Gamma_{t}^{O P}(\psi)$, whose contribution to productivity growth is 5.2 percent for minimills and 5.3 percent for vertically integrated producers. Rather, it was the much higher increase in average plant productivity for vertically integrated producers $\left(\bar{\omega}_{i t}(V I)\right)$ of 18.3 percent, versus a $\bar{\omega}_{i t}(M M)$ of 4.8 percent for minimills.

Our analysis so far points to a large impact of minimill entry on shaping overall industry productivity. We find that about 48 percent of total aggregate productivity growth can directly be attributed to minimills, with 27 percent due to reallocation away from the old technology and the remaining 21 percent due to productivity improvements at minimill plants, which captures learning by doing taking place at minimills 18

\subsubsection{Dynamics: the role of entry and exit}

The above decomposition masks the potential impact of entry and exit on aggregate productivity. The average productivity term $\bar{\omega}$ mixes changes in productivity inside plants, with changes in the distribution of productivity due to entry and exit. A similar concern also affects the measured covariance terms. We turn to this and consider a dynamic version of our decomposition. Let us consider three distinct sets of producers for a given time window $t-1, t$, where $t$ is a ten-year window: incumbents $(\mathcal{A})$, entrants $(\mathcal{B})$ and exiting plants $(\mathcal{C}) 19$ Using these sets, we can write aggregate productivity growth, $\Delta \Omega_{t}$, as:

$$
\underbrace{\sum_{i \in \mathcal{A}} s_{i t-1} \Delta \omega_{i t}}_{\text {Plant Improvement }}+\underbrace{\sum_{i \in \mathcal{A}} \Delta s_{i t} \omega_{i t-1}+\sum_{i \in \mathcal{A}} \Delta s_{i t} \Delta \omega_{i t}}_{\text {Reallocation }}+\underbrace{\sum_{i \in \mathcal{B}} s_{i t} \omega_{i t}}_{\text {Entry }}-\underbrace{\sum_{i \in \mathcal{C}} s_{i t-1} \omega_{i t-1}}_{\text {Exit }} .
$$

\footnotetext{
${ }^{18}$ We do not pursue an explicit analysis of the learning by doing effects at minimills, since our data do not contain the level of detail needed for us to credibly infer this process. See Benkard $(2000)$ for such an analysis and what type of data are key to identifying learning by doing.

${ }^{19}$ This decomposition has been suggested by Davis, Haltiwanger, and Schuh (1996) and has been used in other empirical work by e.g. De Loecker and Konings (2006).
} 
The first term is denoted Plant Improvement, the next two terms on are the Reallocation terms, and the last two terms are the Entry and Exit components. The above decomposition directly isolates the net-entry effect on aggregate productivity by verifying the importance of the last two components in total productivity growth. Finally, to isolate the role of entry and exit for both types of technology separately, we expand the above by computing equation (10) by technology type $\psi$. When we refer to the total impact of reallocation, we group all terms except for the plant-improvement component.

Table 5 presents the decomposition across all plants and by technology. The first row of Table 5 restates the 23-percent productivity growth in the U.S. steel sector, but far faster growth for vertically integrated plants than for minimills.

Across the entire sample period, over which productivity increased by 23 percent productivity growth, within plants accounted for a 10 percent increase in aggregate productivity (or a 43 percent share), while reallocation and net entry are responsible for the remainder. Thus, the total share of reallocation in aggregate productivity growth, including both the reallocation induced by marketshare reallocation across incumbents and the net-entry process, is two-thirds.

A clear picture emerges when we move to the decomposition by technology. The main driver of productivity growth for minimills is the within component of 14.7 percent, capturing the technological change in minimills. This is suggestive of the substantial learning by doing that took place in minimill production - in particular learning how to produce higher quality steel - over the sample period. The reallocation component is negligible.

The same analysis of VI producers yields substantially different results: The plant improvement component, of 10.2 percent, is smaller than that of minimills (14.7 percent), the net entry term of 3.9 percent is almost 19 percent of total productivity growth over the sample. Most noteworthy is that the reallocation term of 11.8 percent is responsible for 48 percent of industry-wide productivity growth.

In the last row of Table 5, we restate the distinct role of the net-entry process across technologies. We present the productivity premium of entrants, compared to the set of exiting plants. Across the entire sample period, VI entrants were 4.4 percent more productive than those VI plants that exited the industry. New minimills, on the other hand, entered with no specific productivity advantage.

To summarize, we find a drastic difference in the role of reallocation between technologies. The productivity growth of minimills is entirely due to common within-plant productivity growth, whereas integrated producers' productivity growth came from the reallocation of resources across producers (67 percent). In the next section, we focus on the role of reallocation among vertically integrated producers, which was instrumental for the productivity growth among producers relying on the old technology, and consequently triggered productivity growth for the industry as a whole.

\subsection{Catching up of the old technology}

So far, we have shown that a substantial part of the industry's productivity growth can be accounted for by the arrival of the new technology and its own technological progress, capturing 
about half of the productivity growth in the industry. The entry of the new technology, however, spurred a dramatic reallocation process in the incumbent technology leading to a sharp increase in productivity - where the exit margin played a key role. It is, therefore, natural to ask how incumbents became more productive. From our various decompositions we already know that the exit of inefficient producers was a key driver, in addition to the reallocation among existing producers.

To uncover the underlying mechanism, we incorporate the product space of the industry. We know from Figure 6 that the market-share trajectories of minimills for, broadly speaking, two product categories - bar products and sheet products - were very different. Indeed, minimills took over bar products, but not sheet products. Therefore we verify whether the substantial productivity gains among (surviving) VI producers over our sample period were related to the product-market competition - i.e., did VI producers of bar products exit, leaving only those VI producers specializing in sheet products? In other words: How important was the increased competition, due to minimill entry, for incumbents's productive efficiency?

The distinction between the two product groups is relevant to the extent that (1) there exists a productivity difference among bar and sheet producers, and (2) survival is related to specialization 20 In order to verify whether this mechanism is important in the data, we first test whether plants specializing in sheet products were, on average, more productive, than those specializing in bar products. Subsequently, we ask whether the product specialization variable predicts plant survival. We run both tests on the total sample of plants in our data, and on the subsample of VI producers. In the latter, we compare plants of the same technology and verify whether product specialization can explain the rapid productivity growth among the group of VI producers.

Table 6 estimates both a technology and sheet-specialization productivity premium for a number of specifications, where sheet specialization refers to the share of a plant's revenue accounted for by sheet products ${ }^{21}$ In Panel A, we consider all plants in the industry, and find a robust and highly significant productivity advantage for plants specializing in sheet products, while controlling for technology, and an exhaustive set of fixed effects. Even if we compare plants of the same technology, within the same firm and state, in the same year, we find a 12 percent productivity premium for plants that completely specialized in sheet. In Panel B, we focus on the VI producers, and find a similar premium. These results, therefore, strongly suggest that the rapid productivity growth of VI producers was due to the reallocation from bar to sheet producers. The latter is consistent with the market-share trajectories presented in Figure 6, which showed MM taking over bar products but not sheet products.

Taking the sheet productivity premium as given, we verify whether VI producers producing primarily sheet products had a higher likelihood of survival. In Table 7, we present survival

\footnotetext{
${ }^{20} \mathrm{~A}$ potential third component would be the change in product specialization at the plant level over time. However, we find very little change in product specialization over time; and thus this mechanism cannot generate within-plant productivity improvements. This finding sits well with our implicit assumption of plant-level productivity.

${ }^{21}$ For all practical purposes, minimills do not produce sheet products. Moreover, there is little year-to-year variation in the share of revenues accounted for by sheet products within a plant. This suggests that it is difficult to alter the product mix at the plant level. Given the lack of within-plant variation in sheet specialization, regressions with plant-level fixed effects will have little power to identify the productivity premia of sheet producers.
} 
regressions, where we run an indicator of plant survival - whether a plant which was in active in 1963, survived until 2002 - against plant technology and sheet specialization 22 In Panel A, we consider all plants in the industry and find that the sheet specialization ratio variable has a strong positive impact on a plant's survival probability, holding fixed its technology. Indeed, a plant that was fully specialized in sheet had a 31-percent-higher probability of surviving than a plant that was fully specialized in bar. This is a very large effect, as plants have a 33-percent likelihood of survival to begin with. Moreover, this effect is robust to controlling for the plant's capital and productivity - standard predictors of plant survival 23

The productivity difference between sheet and bar producers is only relevant to the extent that it exists among integrated producers. In Panel B, we focus on VI producers and find a very similar effect: VI producers specializing in sheet products in 1963 had a 31-percent-higher probability of surviving to the year 2002. We note that predicting plant survival over a forty year period is a very demanding task. Even when our sample size is reduced to 78 VI producers active in 1963, we obtain a t-statistic of 1.6 on the sheet-specialization variable, while controlling for capital and productivity.

Thus, the joint productivity and survival premium for sheet producers helps explain the overall productivity growth of VI producers in the aftermath of minimill entry. Minimills increased competition in the bar market, leading to the exit of inefficient VI producers. As a consequence, the set of remaining VI producers was more productive due to an increased concentration in the sheet product market. This mechanism, therefore, manifests itself in substantially higher productivity of VI producers and a dramatic drop of VI's market share of bar products. In light of our decomposition results, presented in Tables 4 and 5, 34 percent of the industry's productivity growth is due to the reallocation process among VI producers, in which the specialization in sheet products seem to have played a crucial role. To obtain the 34 percent contribution, we use the fact that 67 percent of the VI productivity growth was due to reallocation (Table 5).

Finally, the only component we have not explained is the pure within-plant productivity growth component for VI producers, which, according to our results in Table 5 , accounts for only 13 percent of aggregate TFP growth. This common shift of the production frontier for VI producers captures the direct technological innovations in steel making at integrated plants due to active investments, and improvements in technical efficiency. Put another way, it would be surprising if 40 years of innovation in the engineering and management of vertically integrated plants had not manifested itself in increased productivity. Still, this means that 87 percent of total productivity growth can be attributed to the reallocation induced by minimill entry.

\footnotetext{
${ }^{22}$ These results are robust to looking at survival from 1967, 1972 or even 1977, until 2002. Likewise, these results are also robust to looking at survival until 1997 and 1992.

${ }^{23}$ See Collard-Wexler (2009) and the references therein.
} 


\subsection{Market Power and Reallocation}

The drop in demand for U.S. steel producers and the variation in the market-shares trajectories across products point to drastic changes in competition. We argued that the entry of the minimill intensified competition for domestic steel producers, in particular for the bar segment of the industry (see Section 4.3). In addition to this increased domestic competition, it is well known that international competition intensified through a substantial increase of imports. The increased competition is expected to affect a plant's residual demand curve and, therefore, impact its ability to charge a price above marginal cost. The change in the residual demand elasticity, and its associated markup response, are expected to affect the reallocation across producers, as well.

We rely on our empirical framework to (1) show that markups indeed decreased as competition increased, and (2) show how lower markups are directly related to our measure of reallocation, the covariance of productivity and a plant's market share.

A nice feature of our approach is that we can generate measures of market power from our estimates of the production function. We rely on our production function framework to recover markups by technology type and plant. In order to obtain markups from the plant-level production data, we follow the approach suggested by De Loecker and Warzynski (2012). Appendix C.2 presents the details of this approach. At the core of this approach lies the assumption that plants minimize costs and that at least one input of production faces no adjustment costs.

The two main ingredients of computing markups are the output elasticity of intermediate inputs, such as materials and energy, and the corresponding expenditure share of the input. The latter is directly observed in the data, whereas the output elasticities are recovered after we estimate the production function as discussed above.

We compute markups by technology as obtained from technology-specific aggregate expenditures on an intermediate input $\left(E_{t}(\psi)\right)$, materials in our case, and sales $\left(R_{t}(\psi)\right)$ while relying on a time-invariant Cobb-Douglas output elasticity of the intermediate input $\left(\beta_{m}\right)$ :

$$
\mu_{t}(\psi)=\beta_{m} \frac{R_{t}(\psi)}{E_{t}(\psi)} .
$$

Under the commonly assumed Cobb-Douglas production function these markups are in fact the correct technology-specific markups, with the markup by technology thought of as a weighted average across plants where the weights are the expenditure share on materials of a given plant in the total expenditures for plants of the same technology 24 Figure 4 plots the markup trajectory over 40 years for both MM and VI plants. Markups have steadily decreased over time and are consistent with the drop in prices and external measures of concentration reported for the steel sector. Markups were, on average, higher for minimills, confirming the results from the augmented production function estimation in Table 3 , and this is as expected since they produce more efficiently while competing in the same product market.

\footnotetext{
${ }^{24}$ To see this, use $c_{i \psi t}=\frac{E_{i t}}{E_{t}(\psi)}$ in the share weighted markup expression for a type $\psi$, where $c_{i \psi t}$ is the share of an individual plant in the type's total: $\mu_{t}(\psi)=\sum_{i \in \psi} c_{i \psi t} \mu_{i t}=\sum_{i \in \psi} c_{i \psi t} \beta_{m} \frac{R_{i t}}{E_{i t}}=\beta_{m} \frac{R_{t}(\psi)}{E_{t}(\psi)}$.
} 
Markups fell at the same time as the covariance between output and productivity increases. Suppose that this fall in markups is due to a firms' residual demand curve becoming more elastic. In other words, markups fell because the product market for steel became more competitive. This does not seem unlikely since there are far more steel producers in 2002 than 1963 competing over a roughly similar market size.25

A more elastic residual demand curve will accentuate the relationship between productivity and output. Furthermore, the increase in the residual demand curve for integrated firms is consistent with the increased competition from minimills and a resulting decline in their market share. A similar point is made, in the context of variable markups and trade liberalization, by Edmond, Midrigan, and $\mathrm{Xu}(2012)$ and Mayer, Melitz, and Ottaviano (2011). Thus we expect the extent of competition to be directly linked to reallocation, which is what we find in the data.

\section{Alternative explanations and Robustness Analysis}

In this section, we explore various alternatives that can potentially help explain the sharp increase in productivity growth. It is important to note that these alternatives are not mutual exclusive. The point of this section is not to argue that only technology was responsible for bringing about the efficiency gains. We show that our main results are not affected by controlling for these alternative explanations: Firm-level characteristics, geography, and international trade do not appear to play a role in explaining either the differences in productivity between minimills and vertically integrated producers, or the reallocation between these technologies.

Finally, we present the main results from our decomposition analysis using a variety of productivity estimates (as presented in Table 3). We discuss the robustness of our results, and highlight the importance of our corrections in establishing a prominent role of technology in generating aggregate productivity growth.

\section{$5.1 \quad$ Management practices and ownership}

Our analysis, thus far, has been focused on plants. To the extent that better plants are managed by better firms, we are potentially attributing productivity differences across plants to technology, where it might simply reflect that more-productive plants, regardless which technology they use, are better-managed or belong to more efficiently organized firms. The potential role for firm-level variables explaining productivity differences is, in particular, plausible given the recent findings of Bloom and Van Reenen (2010). They present empirical evidence that measures of productivity, like the one we use, are correlated with various management practices, reflecting human resource (HR) practices and organizational design. Ichniowski, Shaw, and Prennushi (1997) find that better HR practices lead to higher productivity using detailed product-line data. Their results confirm recent theoretical models that stress the importance of complementarities among work practices.

\footnotetext{
${ }^{25}$ Total production in 1965 was about 130 million, and by 2000 is about 112 million tons. Also see Figure 1 where the value of production as well as the number of plants are presented
} 
To check whether the minimill premium in our sample period was not driven by better-managed firms, or any particular kind of firm-specific ownership structure, we compare minimills to VI plants within the same firm and time period using by regressing productivity on technology, and a firmyear fixed effect. Table 8 presents these results. We start out in column I with a base premium of ten percent. We find an almost identical productivity premium, of around ten percent, for minimills when including a firm-time fixed effect (column II).

These results suggest that the minimill productivity premium was not driven by a particular allocation of minimill plants to more-productive firms with, say, better management or human resource (HR) practices. Moreover, our results do not contradict those presented by Ichniowski, Shaw, and Prennushi (1997), who rely on a sample of 17 rolling mills collocated with vertically integrated plants in the United States and, therefore, omit minimills from the analysis. Thus, there is no information on the relative performance of minimills. In addition, they focus on rolling operations, which we purposefully leave out ${ }^{26}$

Finally, including firm fixed effects does not rule out an effect of management. If management practices differ between plants at the same firm, and these intra-firm differences in management are precisely aligned with the technology used in production, then we could still attribute management effects to minimills. However, while we think that this story is very unlikely, it would take historical plant-level data on management to rule it out, and, Census data during our sample period do not track this type of information 27

\subsection{Geography}

Although steel production has historically been concentrated in a few regions in the U.S., there is still considerable variation of activity across regions. In 2002, 63 percent of steel was produced in the Midwest - i.e., Illinois, Indiana, Michigan, Ohio, and Pennsylvania - while this figure was 75 percent in 1963. We check whether regional patterns influence our results by incorporating a full set of state-year dummies, in a regression of productivity on our measure of technology. Table 8 shows that the substantial minimill premium is largely unaffected when including state-time fixed effects. This result reflects that minimills are, on average, 12.9 percent more productive than integrated producers in the same state and year (column III). Furthermore, this result is robust with respect to including technology-year interactions.

Finally, in column IV, we include a joint firm-state-year fixed effect and find that the technology premium is still strongly positive and significant, but with a point estimate of 25 percent. This suggests that minimills are vastly more productive, even when we compare a minimill and a vertically integrated plant owned by the same firm, and located in the same state. The results in Table 8 indicate that the productivity premium for minimills is extremely robust, and is not an

\footnotetext{
${ }^{26}$ The main reason to omit rolling mills is because the boundary between rolling operations and other steel shaping operations, such as pipe making or other more artisanal iron work, is less clear. By focusing on the production of molten steel, we obtain a sharper definition of the industry.

${ }^{27}$ The new wave of economic Census will contain a Management and Organization Practices Survey (MOPS). See World Management Survey and http://bhs.econ/census.gov/bhs/mops/for more on this recent addition.
} 
artifact of a particular selection mechanism at the firm or regional level, or an interplay of both.

\subsection{International Trade}

It is well documented that the U.S. steel sector has faced stronger competition from foreign producers over the course of the last four decades. However, for our purposes, the relevant question is whether the mere increase in import competition could explain the rapid productivity growth in the industry.

Table 9 lists the average productivity growth and import penetration ratio across the US manufacturing industries (4-digit SIC codes), and compares them with the steel industry. The upper panel lists the absolute imports and shows that the steel sector's imports did not increase nearly as much as the modal manufacturing industry.

The bottom panel reports the import penetration ratio and highlights that international competition increased across all U.S. manufacturing industries, and that steel was no exception. However, both in an unweighted and weighted sense, the change in international competition for U.S. steel was lower than the average across all sectors of US manufacturing. Productivity growth in the steel industry, as documented previously in Table1, has been three times higher than the average. While we see increased import competition for domestic steel producers, this, by itself, cannot explain the exceptional improvements in productivity.

Using the statistical relationship between productivity growth and the change in the import penetration ratio, over the period 1972-1996, we would predict only an eight percent productivity growth for the steel industry ${ }^{28}$ Put differently: The change in international competition can explain at most one third of the productivity growth.

These types of estimates are further subject to various biases and measurement problems. For instance, the Semiconductor industry experienced remarkable productivity growth, while its import penetration ratio increased as well. However, the import surge was due to U.S. producers outsourcing production while focusing on R\&D and design in the U.S. affiliates. Identifying the impact of foreign competition on industry performance is further complicated due to endogenous changes in international competition, as well as to reversed causality from productivity growth to international trade.

In this paper, we focus on a clean and directly measurable source of productivity growth: the arrival of a new technology. The potential role of international trade in affecting productivity growth indirectly is further weakened since the specific trajectory of imports, or any alternative measure of international competition, is not aligned with the arrival of the new technology. We do acknowledge, as shown in Table 9, that changes in international competition did most likely

\footnotetext{
${ }^{28}$ We construct a matched production-trade database at the 4-digit SIC87 level using the NBER Manufacturing Database and the U.S. Trade Database. We consider a simple long difference regression of TFP growth on the change in the import penetration ratio. The estimated coefficients are used to predict the steel industry's productivity growth. Specifically, we run the following regression: $\Delta \Omega_{I}=\gamma_{0}+\gamma_{1} \Delta I P R_{I}+\nu_{I}$ across the entire sample of 4-digit SIC87 industries, where $\Delta$ is the difference over the 1972-1996 period, and we weigh observations by the industry's share in total manufacturing production.
} 
affect domestic producers by shifting in the residual demand for steel products. In this sense, the increased competition introduced by minimills was reinforced, if anything, by competing over a smaller market share, a mechanism we account for in our analysis of markups.

Finally, one might still worry that the effects of international competition were more pronounced for integrated producers than for minimills, thereby affecting the interpretation of our results. Therefore, we checked whether the measures of international competition, such as import shares, differed across products. As discussed previously, minimills were mainly active in the bar segment, especially in the period 1972-1996, where we observe good measures of international competition (also see Figure 2). When we break down imports and exports by product, we find that imports show a rise for bar products produced by minimills that is similar to that of sheet products, which minimills do not produce.

In addition, since minimills were historically more concentrated in the midwest, while integrated producers were active in coastal areas, we might worry that minimills were more insulated from foreign competition due to substantial intranational shipping costs. However, in the previous subsection we discussed the robust productivity advantage of minimills when controlling for regional differences.

\subsection{Importance of Corrections and Robustness}

Tables 10 and 11 presents robustness checks on our main decompositions of aggregate productivity growth, both static and dynamic. For each of the productivity estimates obtained using the specifications listed in Table 3 , we produce the static and dynamic decompositions.

The first column of Tables 10 and 11 rely on productivity estimates obtained using the production function coefficients of specification VI in Table 3. We contrast these to results obtained using productivity estimates obtained without correcting for unobserved price differences across producers, and to results obtained without correcting for simultaneity and selection. To assess the precision of our results, we include bootstrapped confidence intervals on the share of each component for all decompositions.

\subsubsection{Robustness}

We find that our decompositions are qualitatively robust to alternative specifications of the production function. We find similar differences in the speed of productivity growth between technologies, a far larger role for reallocation among the vertically integrated producers than among the minimills, and a large role for the between covariance in productivity growth.

The various components of the decompositions use plant-level estimates of productivity, which rely on estimated production function coefficients, and thus are also estimates. We use a block bootstrap routine to produce confidence intervals of the shares of each component. The 95 percent confidence intervals around the various shares are reasonably tight ${ }^{29}$ For example the confidence

\footnotetext{
${ }^{29}$ As far as we know, this is the first paper to produce confidence intervals around the components of the decomposition of (an industry's) aggregate productivity, and we cannot compare our results to existing work.
} 
interval around aggregate productivity growth is similar across all specifications.

\subsubsection{Importance of Corrections}

The results in Tables 10 and 11, also point out the importance of correcting for unobserved productivity and price errors when estimating the production function, to obtain the correct quantitative effects of the entry of minimills on aggregate productivity. What is particularly sensitive to the specification of the production function is the between decomposition. Indeed, the between component is 27 percent in Column VI (GMM and price correction), as opposed to 11 percent using OLS productivity estimates in Column I (OLS). These differences are statistically significant as the confidence intervals for the between share do not overlap between these two columns. This is not too surprising, as Table 3 showed that the minimill productivity premium was far larger in Column VI, than in Column I. These difference in the estimated productivity advantages of minimills directly spill over to the estimated magnitude of the between covariance. Further controlling for differences in input price trends across plants does not change the results.

The role of entry and exit is altered by omitting to correct for price and productivity errors in the production function. The impact of the exit process of integrated producers is cut in half (from 19 to 8 percent between Column VI and I), while the within-plant minimill improvements are underestimated (107 versus 79 percent from Column VI to I). These findings echo the results of Foster, Haltiwanger, and Syverson (2008): Correcting for variation in plant-level prices is crucial to obtain reliable productivity measures, and more importantly, to measure the impact of entry and exit, an important part of our reallocation mechanism, on aggregate productivity.

Summing up, if we incorrectly ignored price variation across producers, the endogeneity of inputs and the non-random exit of plants in the data, we would underestimate the reallocation mechanism by a factor of two. Our results suggest that the total effect of minimill entry on industry-wide productivity growth was 87 percent. This share drops to about 72 percent when ignoring unobserved price and productivity heterogeneity. However, although we find a much larger magnitude, the role of technology is present when using uncorrected productivity estimates, which adds to the robustness of the importance of our specific reallocation mechanism.

\section{Conclusion}

There is by now extensive evidence that reallocation of resources across producers substantially impacts productivity growth. This paper is one of the first to provide a specific mechanism underlying such a reallocation: The entry of a new technology, and its associated increased competition, were largely responsible for the massive productivity growth in the U.S. steel industry.

We provide evidence that technological change can, by itself, bring about a process of resource

reallocation over a long period of time and lead to substantial productivity growth for the industry as a whole. We find that the introduction of a new production technology spurred productivity growth through two channels. 
First, the entry of minimills lead to a slow but steady drop in the market share of the incumbent technology, the vertically integrated producers. As minimills were 11 percent more productive, this movement of market share between technologies was responsible for a third of the industry's productivity growth. Second, while the new technology started out with a 25 percent productivity premium, by the end of the sample, minimills and vertically integrated producers were very similar in terms of efficiency. This catching-up process of the incumbents came about from a large within reallocation of resources among vertically integrated plants.

The reallocation among vertically integrated plants was largely due the exit of inefficient producers active in the low-quality segment (bar products.) On the other hand, minimills's productivity increased gradually over time due to a shift in the production function for all minimill producers. Although the first mimimill, producing at a commercial level, entered in the late fifties, the productivity effects were long-lasting and still affect the industry's performance today. In fact, the recent trend in market shares suggests that minimills started to enter the high-quality segment of the industry - sheet products - and taking our results at face value would indicate that more substantial productivity gains are expected.

Our results indicate that the arrival of new technologies can have a major impact on productive efficiency through increased competition and its associated reallocation of economic resources, leading to an increase in the industry's overall performance. It is critical to obtain measures of plant-level performance and technology to identify this mechanism - i.e., without indicators of technology at the plant-level, we would falsely attribute the productivity gains to other factors correlated with aggregate productivity, such as international competition, geography, and a variety of firm-level characteristics.

\section{References}

Ackerberg, D., L. Benkard, S. Berry, and A. Pakes (2007): "Econometric Tools for Analyzing Market Outcomes," in Handbook of Econometrics, ed. by J. Heckman, and E. Leamer, vol. 6a, chap. 63, pp. 4171-4276. Elsevier.

Ackerberg, D., G. Frazer, and K. Caves (2006): "Structural Estimation of Production Function," Working Paper UCLA.

American Iron And Steel Institute (2010): Annual Statistical Report of the American Iron and Steel Institute. Washington D.C.

Bartelsman, E., R. Becker, And W. Gray (2000): "Nber-ces manufacturing industry database," Last accessed May, 25, 2006.

Bartelsman, E., J. Haltiwanger, and S. Scarpetta (2009): "Cross-country differences in productivity: the role of allocation and selection," Discussion paper, NBER Working Paper.

Benkard, C. (2000): "Learning and Forgetting: The Dynamics of Aircraft Production," American Economic Review, 90(4), 1034-1054. 
Bernard, A., J. Jensen, and P. Schott (2006): "Survival of the best fit: Exposure to lowwage countries and the (uneven) growth of US manufacturing plants," Journal of International Economics, 68(1), 219-237.

Bloom, N., B. Eifert, A. Mahajan, D. McKenzie, and J. Roberts (2011): "Does management matter? Evidence from India," Discussion paper, National Bureau of Economic Research.

Bloom, N., And J. VAn ReEnen (2010): "Why do management practices differ across firms and countries?," The Journal of Economic Perspectives, pp. 203-224.

Bresnahan, T. F., and D. M. G. Raff (1991): "Intra-Industry Heterogeneity and the Great Depression: The American Motor Vehicles Industry, 1929-1935," The Journal of Economic History, $51(2), 317-331$.

Collard-Wexler, A. (2009): "Productivity Dispersion and Plant Selection in the Ready-Mix Concrete Industry," Working Paper, New York University.

Crandall, R. (1981): The US steel industry in recurrent crisis: policy options in a competitive world. Brookings Institution Press.

Davis, S. J., J. C. Haltiwanger, and S. Schuh (1996): Job creation and destruction. MIT Press Cambridge, Mass.

De Loecker, J. (2011): "Product Differentiation, Multiproduct Firms, and Estimating the Impact of Trade Liberalization on Productivity," Econometrica, 79(5), 1407-1451.

De Loecker, J., P. Goldberg, A. Khandelwal, and N. Pavcnik (2012): "Prices, Markups and Trade Reform," Discussion paper, National Bureau of Economic Research.

De Loecker, J., And J. Konings (2006): "Job reallocation and productivity growth in a postsocialist economy: Evidence from Slovenian manufacturing," European Journal of Political Economy, 22(2), 388-408.

De Loecker, J., And F. Warzynski (2012): "Markups and firm-level export status," American Economic Review, 102(6), 2437-2471.

Edmond, C., V. Midrigan, and D. Xu (2012): "Competition, markups, and the gains from international trade," Discussion paper, National Bureau of Economic Research.

Foster, L., J. Haltiwanger, and C. KRizan (2001): "Aggregate productivity growth. Lessons from microeconomic evidence," in New developments in productivity analysis. University of Chicago Press.

Foster, L., J. Haltiwanger, and C. Syverson (2008): "Reallocation, Firm Turnover, and Efficiency: Selection on Productivity or Profitability?," American Economic Review, 98(1), 394425 .

Fruehan, R. (1998): The Making, Shaping and Treating of Steel - 11th Edition. AISE Steel Foundation, Pittsburgh, USA.

Giarratani, F., G. Gruver, and R. Jackson (2007): "Clusters, agglomeration, and economic development potential: empirical evidence based on the advent of slab casting by US steel minimills," Economic Development Quarterly, 21(2), 148-164. 
Hall, C. (1997): Steel phoenix: The fall and rise of the US steel industry. Palgrave Macmillan.

Hoerr, J. (1988): And the wolf finally came: The decline of the American steel industry. University of Pittsburgh Press Pittsburgh.

Hortaçsu, A., And C. Syverson (2004): "Cementing Relationships: Vertical Integration, Foreclosure, Productivity, and Prices," .

Ichniowski, C., K. Shaw, and G. Prennushi (1997): "The Effects of Human Resource Management Practices on Productivity: A Study of Steel Finishing Lines," American Economic Review, 87(3), 291-313.

Jarmin, R., S. Klimek, and J. Miranda (2009): "The Role of Retail Chains: National, Regional and Industry Results," in Producer Dynamics: New Evidence from Micro Data, pp. 237-262. University of Chicago Press.

Mayer, T., M. Melitz, and G. Ottaviano (2011): "Market size, competition, and the product mix of exporters," Discussion paper, National Bureau of Economic Research.

Melitz, M. (2003): "The Impact of Trade on Intra-Industry Reallocations and Aggregate Industry Productivity," Econometrica, 71(6), 1695-1725.

Olley, G. S., And A. Pakes (1996): "The dynamics of productivity in the telecommunications equipment industry," Econometrica, 64(6), 35.

Oster, S. (1982): "The Diffusion of Innovation among Steel Firms: The Basic Oxygen Furnace," The Bell Journal of Economics, 13(1), pp. 45-56.

Rogers, R. (2009): An economic history of the American steel industry. Taylor \& Francis.

Schmitz, J. (2005): "What determines productivity? Lessons from the dramatic recovery of the US and Canadian iron ore industries following their early 1980s crisis," Journal of Political Economy, 113(3), 582-625.

Syverson, C. (2011): "What Determines Productivity?," Journal of Economic Literature, 49(2), 326-65.

Van Biesebroeck, J. (2003): "Productivity dynamics with technology choice: An application to automobile assembly," The Review of Economic Studies, 70(1), 167-198. 


\section{TABLES AND FIGURES}

Table 1: Relative Performance of the steel sector

\begin{tabular}{cccc} 
Sector & $\Delta$ TFP & $\Delta$ Shipments & $\Delta$ Labor \\
\hline Steel Sector & $28 \%$ & $-35 \%$ & $-80 \%$ \\
Mean Sector & $7 \%$ & $60 \%$ & $-5 \%$ \\
Median Sector & $3 \%$ & $61 \%$ & $-1 \%$
\end{tabular}

Source: NBER-CES Dataset for SIC Code 3312. Note: Only sectors over 10 billion dollars are included. Changes computed between 1972-2002.

1963-1972

1973-1982

1983-1992

1993-2002

$\underline{\text { Minimills }}$

1963-1972

1973-1982

1983-1992

1993-2002

Vertically Integrated

1963-1972

1973-1982

1983-1992

1993-2002
Table 2: Entry and Exit in U.S. steel

\begin{tabular}{rr} 
Entrant Market Share (Plants) & Exitor Market Share (Plants) \\
\cline { 2 - 2 } $6(29)$ & $9(\mathrm{D} *)$ \\
$5(49)$ & $20(20)$ \\
$21(55)$ & $18(47)$ \\
$12(30)$ & $2(41)$ \\
& Entrants \\
\hline 17 & $\frac{\text { Exitors }}{\mathrm{D} *}$ \\
39 & 0 \\
43 & 26 \\
$\mathrm{D} *$ & 17 \\
& \\
Entrants & Exitors \\
12 & $\mathrm{D} *$ \\
10 & 20 \\
12 & 21 \\
$\mathrm{D} *$ & 24
\end{tabular}

Note: D* cannot be disclosed due to the small number of observations. Numbers refer to the revenue market share represented by exitors and entrants, while numbers in parenthesis refer to the count of plants that enter or exit. 


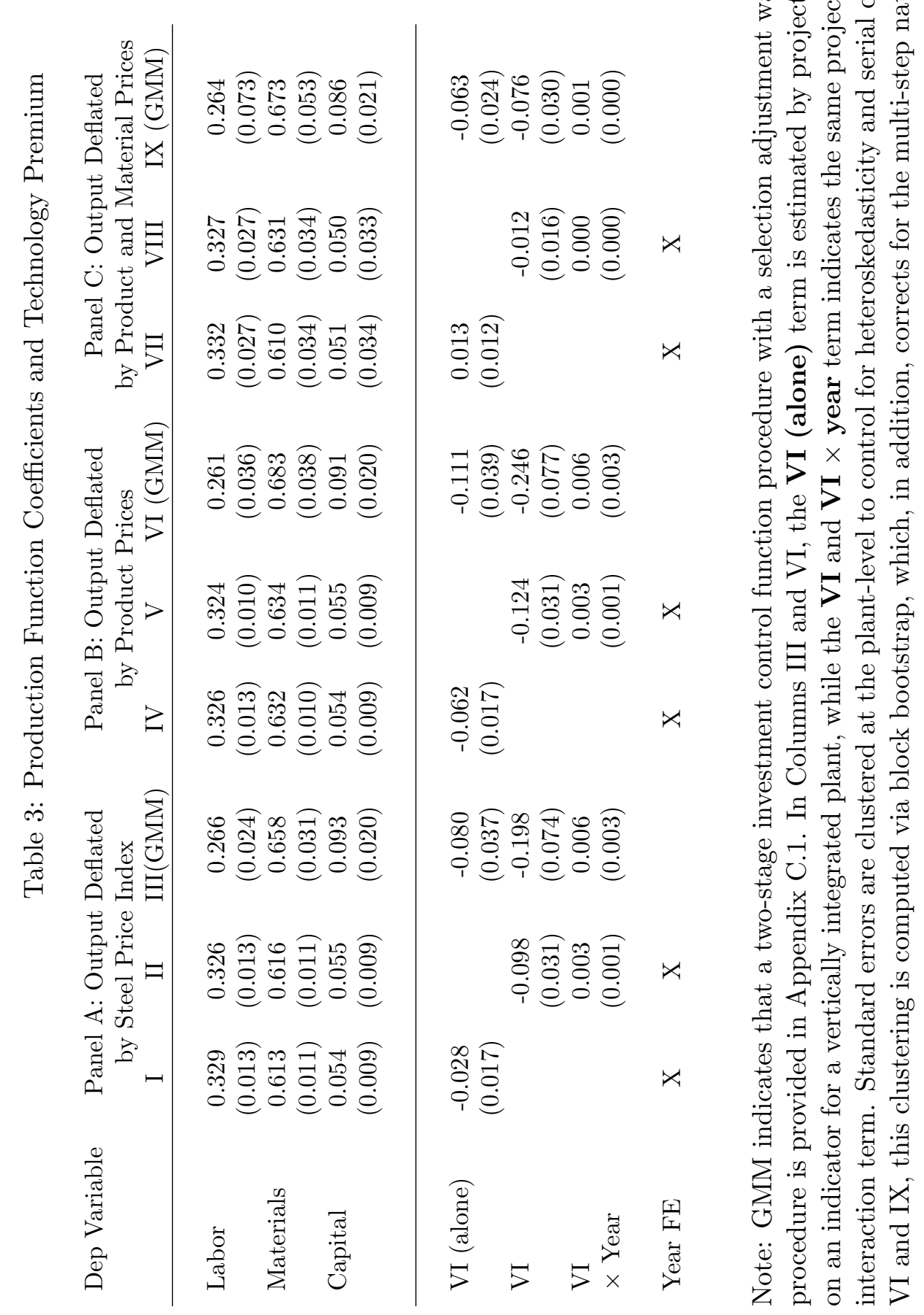


Table 4: Static Decompositions of Productivity Growth (Change 1963-2002)

\begin{tabular}{lrl} 
Aggregate TFP $\Delta \Omega$ & $23.0 \%$ & \\
Olley-Pakes Decomposition: & & \\
Unweighted Average: $\Delta \bar{\omega}$ & $15.5 \%(0.67)$ & \\
Covariance: $\Delta \Gamma^{O P}$ & $7.5 \%(0.33)$ & \\
Between Decomposition: & & \\
\hline Unweighted Average: $\Delta \bar{\Omega}$ & $16.8 \%(0.73)$ & \\
Between Covariance: $\Delta \Gamma^{B}$ & $6.3 \%(0.27)$ & \\
& & \\
Within Decomposition: & Minimills & Integrated \\
Aggregate TFP: $\Delta \Omega(\psi)$ & $10.0 \%$ & $23.6 \%$ \\
Unweighted Average: $\Delta \bar{\omega}(\psi)$ & $4.8 \%(0.48)$ & $18.3 \%(0.78)$ \\
Within Covariance: $\Delta \Gamma^{O P}(\psi)$ & $5.2 \%(0.52)$ & $5.3 \%(0.22)$
\end{tabular}

Note: The share of each component in the total aggregate productivity growth is listed in parentheses.

Table 5: Dynamic Decomposition of Productivity Growth

\begin{tabular}{lrrr} 
Component & All & Minimill & Integrated \\
\hline Total Change & $23.0 \%$ & $10.0 \%$ & $23.6 \%$ \\
& & $(0.21)$ & $(0.52)$ \\
\hline Plant Improvement & $10.2 \%$ & $14.7 \%$ & $10.2 \%$ \\
& & $(0.23)$ & $(0.17)$ \\
Reallocation & $10.6 \%$ & $-1.5 \%$ & $11.8 \%$ \\
& & $(-0.1)$ & $(0.25)$ \\
Net Entry & $3.9 \%$ & $-0.8 \%$ & $3.9 \%$ \\
& & $(0.0)$ & $(0.10)$ \\
& & & \\
\hline Entry-Exit Premium & & $0.0 \%$ & $4.4 \%$
\end{tabular}

Note: The share of each component in the total aggregate productivity growth is listed in parentheses. See equation 10 for definitions of various terms. 


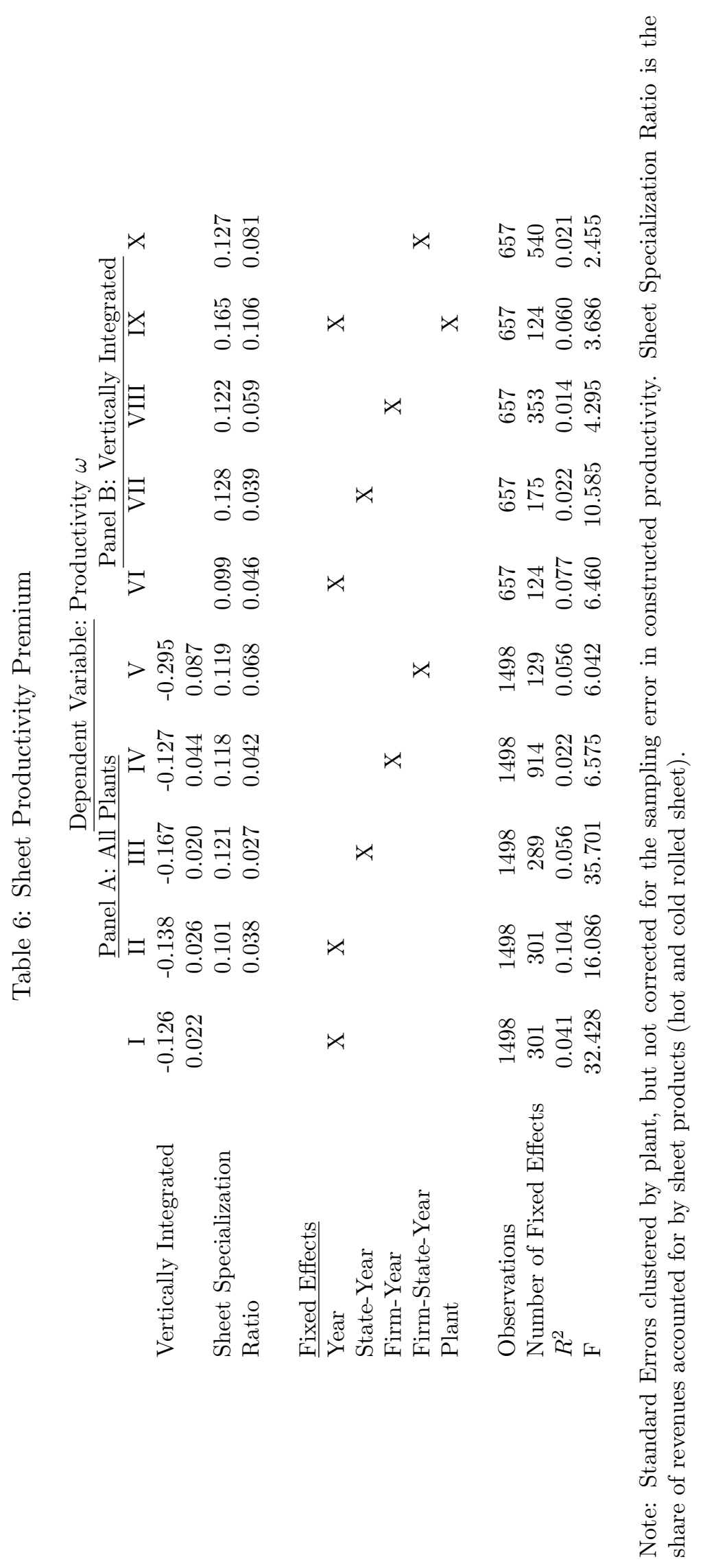


Table 7: Determinants of Exit

Dependent Variable: Plant Exists in 2002 Panel A: All Plants Panel B: Vertically Integrated

Vertically Integrated I $-0.36^{* * *} \quad-0.39^{* * *}$

III IV $\quad \mathrm{V}$

Sheet Specialization Ratio

Log Capital $(k)$

$(0.09) \quad(0.08)$

$0.39^{* *} \quad 0.36^{*}$

$0.31^{*} \quad 0.31^{*}$

0.22

$(0.14)$

$(0.14)$

0.02

$(0.13) \quad(0.13)$

$(0.14)$

$(0.03)$

0.20

0.33

Productivity $(\omega)$

0.04

(0.24)

$(0.26)$

(0.14)

0.06

$(0.04)$

Observations

Log-Likelihood

128
-73.88
16.97
0.33

128
-73.69
17.35
0.32

$\begin{array}{cc}78 & 78 \\ -40.36 & -40.02 \\ 5.89 & 6.58 \\ 0.23 & 0.23\end{array}$

78

$-38.88$

8.84

Baseline Probability

0.33

0.32

$0.23 \quad 0.23$

0.22

Note: Marginal Effects presented. Dependent variable is whether the plant has not exited by 2002 given it's status in 1963. Very similar results are found with 1972 and 1977 as base years.

Table 9: International Competition: Comparing the Steel Sector to US Manufacturing

\begin{tabular}{cccc} 
& \multicolumn{2}{c}{ Change Total Imports } & \\
\cline { 2 - 3 } Period & Steel & Average & Median \\
\hline$\% \Delta[72-02]$ & 4.1 & 66.1 & 23.7 \\
& & & \\
& Import & Penetration Rate & \\
\cline { 2 - 4 } Year & Steel & Average & Weighted Average \\
\hline 1972 & 0.099 & 0.066 & 0.055 \\
1996 & 0.180 & 0.220 & 0.157 \\
\hline Change & 0.081 & 0.154 & 0.102 \\
\% Change & 81 & 233 & 85
\end{tabular}

Note: The average and weighted average are computed over all available 4-digit SIC87 industries using data provided by the NBER Manufacturing Database (for shipment data) and Bernard, Jensen, and Schott (2006) (for import penetration data). The changes are computed by industry before taking averages. The import penetration rate data is available only up to 1996. Weights are based on the industry's share of shipments in total manufacturing shipments as recorded in the NBER Manufacturing Database. 


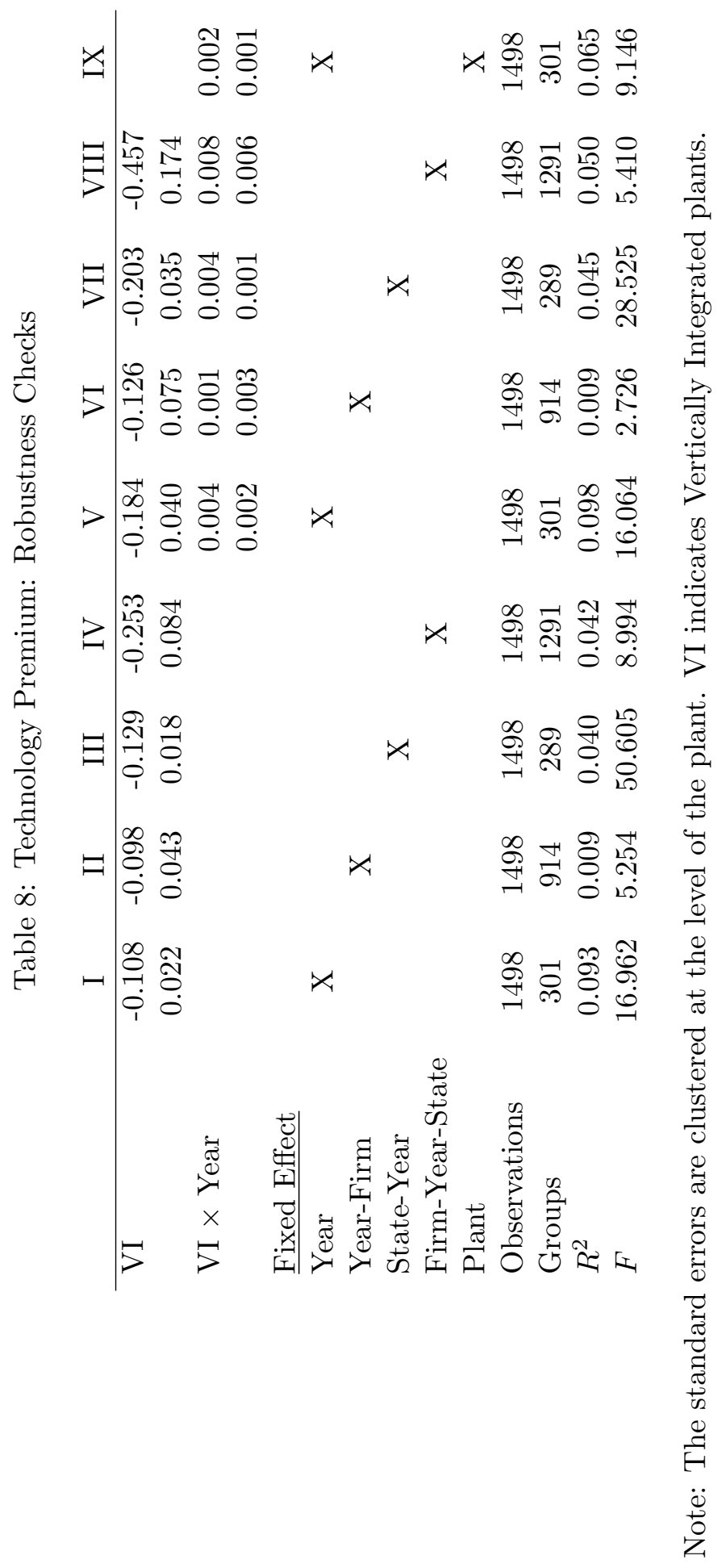


Table 10: Static Decompositions under Alternative Productivity Measures

Specification in Table 3

\begin{tabular}{|c|c|c|c|c|c|c|}
\hline & VI & III & IX & & IV & VII \\
\hline GMM & $\mathrm{X}$ & $\mathrm{X}$ & $\mathrm{X}$ & & & \\
\hline Plant-Level Output Prices & $\mathrm{X}$ & & $\mathrm{X}$ & & $\mathrm{X}$ & $\mathrm{X}$ \\
\hline Plant-Level Material Prices & & & $\mathrm{X}$ & & & $\mathrm{X}$ \\
\hline Change in $\operatorname{TFP}(\Delta \Omega)$ & $\begin{array}{c}0.23 \\
{[0.170 .28]}\end{array}$ & $\begin{array}{c}0.25 \\
{[0.190 .29]}\end{array}$ & $\begin{array}{cc}0.21 \\
{[0.16} & 0.26]\end{array}$ & 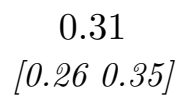 & 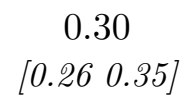 & 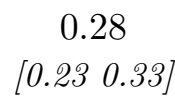 \\
\hline \multicolumn{7}{|l|}{ Olley-Pakes } \\
\hline 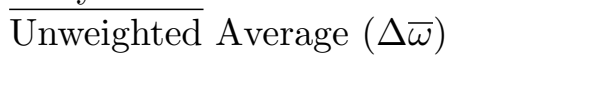 & $67 \%$ & $74 \%$ & $68 \%$ & $74 \%$ & $69 \%$ & $69 \%$ \\
\hline Covariance $\left(\Delta \Gamma^{O P}\right)$ & 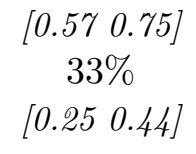 & $\begin{array}{c}{\left[\begin{array}{ll}0.66 & 0.81\end{array}\right]} \\
26 \% \\
{\left[\begin{array}{lll}0.19 & 0.34\end{array}\right]}\end{array}$ & 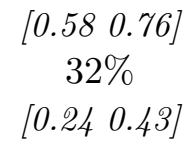 & $\begin{array}{c}{\left[\begin{array}{lll}0.69 & 0.78\end{array}\right]} \\
26 \% \\
{\left[\begin{array}{lll}0.22 & 0.31\end{array}\right]}\end{array}$ & $\begin{array}{c}{\left[\begin{array}{ll}0.63 & 0.73\end{array}\right]} \\
31 \% \\
{\left[\begin{array}{lll}0.27 & 0.37\end{array}\right]}\end{array}$ & $\begin{array}{c}{\left[\begin{array}{ll}0.62 & 0.73\end{array}\right]} \\
32 \% \\
{\left[\begin{array}{ll}0.27 & 0.38\end{array}\right]}\end{array}$ \\
\hline \multicolumn{7}{|l|}{ Between } \\
\hline$\overline{\text { Change in } \bar{\Omega}}$ & $\begin{array}{c}73 \% \\
{[0.630 .80]}\end{array}$ & 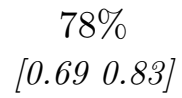 & $\begin{array}{c}77 \% \\
{[0.690 .84]}\end{array}$ & $\begin{array}{c}89 \% \\
{[0.85 \quad 0.92]}\end{array}$ & $\begin{array}{c}87 \% \\
{[0.820 .90]}\end{array}$ & 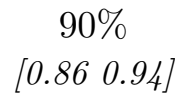 \\
\hline Change in Between Technology & $27 \%$ & $22 \%$ & $23 \%$ & $11 \%$ & $13 \%$ & $10 \%$ \\
\hline Covariance $\left(\Delta \Gamma^{B}\right)$ & {$\left[\begin{array}{ll}0.20 & 0.37\end{array}\right]$} & {$\left[\begin{array}{ll}0.17 & 0.31\end{array}\right]$} & {$\left[\begin{array}{ll}0.16 & 0.31\end{array}\right]$} & {$\left[\begin{array}{lll}0.08 & 0.15\end{array}\right]$} & {$\left[\begin{array}{ll}0.10 & 0.18\end{array}\right]$} & {$\left[\begin{array}{ll}0.06 & 0.14\end{array}\right]$} \\
\hline \multicolumn{7}{|l|}{ Within Technology } \\
\hline \multicolumn{7}{|l|}{$\overline{\text { Minimills }}$} \\
\hline Change in TFP & 0.43 & 0.50 & 0.40 & 0.77 & 0.74 & 0.74 \\
\hline (ratio to aggregate $\frac{\Delta \Omega(M M)}{\Delta \Omega}$ ) & {$\left[\begin{array}{ll}0.19 & 0.60\end{array}\right]$} & {$\left[\begin{array}{lll}0.29 & 0.64\end{array}\right]$} & {$\left[\begin{array}{ll}0.18 & 0.60\end{array}\right]$} & {$\left[\begin{array}{lll}0.64 & 0.87\end{array}\right]$} & {$\left[\begin{array}{ll}0.61 & 0.85\end{array}\right]$} & {$\left[\begin{array}{ll}0.59 & 0.85\end{array}\right]$} \\
\hline Fraction from Unweighted Average & $48 \%$ & $71 \%$ & $51 \%$ & $70 \%$ & $61 \%$ & $62 \%$ \\
\hline$(\Delta \bar{\omega}(M M))$ & {$\left[\begin{array}{lll}-0.22 & 0.64\end{array}\right]$} & {$\left[\begin{array}{ll}0.51 & 0.79\end{array}\right]$} & {$\left[\begin{array}{ll}-0.06 & 0.68\end{array}\right]$} & {$\left[\begin{array}{lll}0.64 & 0.76\end{array}\right]$} & {$\left[\begin{array}{ll}0.52 & 0.68\end{array}\right]$} & {$\left[\begin{array}{lll}0.53 & 0.69\end{array}\right]$} \\
\hline Fraction from Covariance & $52 \%$ & $29 \%$ & $49 \%$ & $30 \%$ & $39 \%$ & $38 \%$ \\
\hline$\left(\Delta \Gamma^{O P}(M M)\right)$ & {$\left[\begin{array}{lll}0.36 & 1.22\end{array}\right]$} & {$\left[\begin{array}{ll}0.21 & 0.49\end{array}\right]$} & {$\left[\begin{array}{lll}0.33 & 1.06\end{array}\right]$} & {$\left[\begin{array}{lll}0.24 & 0.36\end{array}\right]$} & {$\left[\begin{array}{lll}0.32 & 0.48\end{array}\right]$} & {$\left[\begin{array}{ll}0.31 & 0.47\end{array}\right]$} \\
\hline \multicolumn{7}{|l|}{ Vertically Integrated } \\
\hline Change in TFP & 1.03 & 1.05 & 1.13 & 1.01 & 0.99 & 1.07 \\
\hline (ratio to aggregate $\frac{\Delta \Omega(V I)}{\Delta \Omega}$ ) & {$\left[\begin{array}{ll}0.96 & 1.10\end{array}\right]$} & {$\left[\begin{array}{lll}0.99 & 1.13\end{array}\right]$} & {$\left[\begin{array}{ll}1.05 & 1.24\end{array}\right]$} & {$\left[\begin{array}{lll}0.96 & 1.07\end{array}\right]$} & {$\left[\begin{array}{lll}0.94 & 1.04\end{array}\right]$} & {$\left[\begin{array}{lll}1.01 & 1.14\end{array}\right]$} \\
\hline Fraction from Unweighted Average & $77 \%$ & $85 \%$ & $80 \%$ & $82 \%$ & $75 \%$ & $76 \%$ \\
\hline$(\Delta \bar{\omega}(V I))$ & {$\left[\begin{array}{ll}0.68 & 0.88\end{array}\right]$} & {$\left[\begin{array}{ll}0.78 & 0.94\end{array}\right]$} & {$\left[\begin{array}{ll}0.71 & 0.89\end{array}\right]$} & {$\left[\begin{array}{ll}0.77 & 0.87\end{array}\right]$} & {$\left[\begin{array}{ll}0.69 & 0.81\end{array}\right]$} & {$\left[\begin{array}{lll}0.70 & 0.82\end{array}\right]$} \\
\hline Fraction from Covariance & $23 \%$ & $15 \%$ & $20 \%$ & $18 \%$ & $25 \%$ & $24 \%$ \\
\hline$\left(\Delta \Gamma^{O P}(V I)\right)$ & {$\left[\begin{array}{ll}0.12 & 0.33\end{array}\right]$} & {$\left[\begin{array}{ll}0.06 & 0.22\end{array}\right]$} & {$\left[\begin{array}{ll}0.11 & 0.29\end{array}\right]$} & {$\left[\begin{array}{ll}0.13 & 0.24\end{array}\right]$} & {$\left[\begin{array}{ll}0.19 & 0.31\end{array}\right]$} & {$\left[\begin{array}{ll}0.18 & 0.30\end{array}\right]$} \\
\hline
\end{tabular}

Note: GMM refers to the Olley-Pakes control function approach. Plant-level output prices refers to deflating revenue using product level prices indexes. Plant-level material prices refers to deflating material inputs costs using material specific price indexes. Bootstrapped 95\% confidence intervals using 10,000 replications shown in brackets, and these only include sampling error in the computation of productivity $\omega$. 
Table 11: Dynamic Decompositions under Alternative Productivity Measures

Specification in Table 3

\begin{tabular}{ll|cc|ccc} 
& VI & III & IX & I & IV & VII \\
\hline GMM & X & X & X & & & X \\
Plant-Level Output Prices & X & & X & & X & X
\end{tabular}

Dynamic Decomposition

\section{All}

Plant Improvement

Reallocation

Entry-Exit

\section{Minimills}

Plant Improvement

Reallocation

Entry-Exit

\section{Vertically Integrated}

Plant Improvement

Reallocation

Entry-Exit

\begin{tabular}{c|cc|ccc}
$34 \%$ & $41 \%$ & $40 \%$ & $46 \%$ & $41 \%$ & $45 \%$ \\
{$[0.230 .42]$} & {$[0.340 .47]$} & {$[0.330 .48]$} & {$[0.410 .50]$} & {$[0.360 .46]$} & {$[0.400 .50]$} \\
$47 \%$ & $43 \%$ & $46 \%$ & $40 \%$ & $42 \%$ & $42 \%$ \\
{$[0.390 .58]$} & {$[0.370 .52]$} & {$[0.370 .56]$} & {$[0.360 .46]$} & {$[0.380 .49]$} & {$[0.370 .49]$} \\
$19 \%$ & $16 \%$ & $14 \%$ & $14 \%$ & $16 \%$ & $12 \%$ \\
{$[0.170 .22]$} & {$[0.140 .18]$} & {$[0.110 .17]$} & {$[0.130 .15]$} & {$[0.150 .17]$} & {$[0.110 .13]$}
\end{tabular}

$$
\begin{aligned}
& \begin{array}{c|cc|ccc}
107 \% & 119 \% & 130 \% & 90 \% & 79 \% & 86 \% \\
{[0.872 .25]} & {[1.012 .11]} & {[0.952 .59]} & {[0.831 .08]} & {[0.730 .93]} & {[0.771 .03]}
\end{array} \\
& \begin{array}{lll|lll}
-9 \% & -12 \% & -5 \% & -1 \% & 4 \% & 5 \%
\end{array}
\end{aligned}
$$

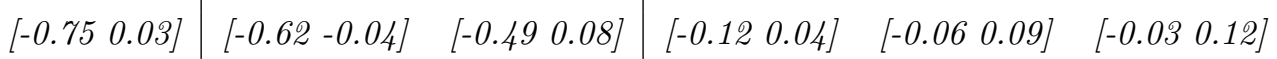

$$
\begin{aligned}
& \begin{array}{l|ll|lll}
0 \% & -6 \% & -25 \% & 11 \% & 18 \% & 8 \%
\end{array}
\end{aligned}
$$

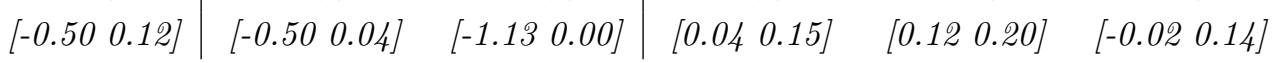

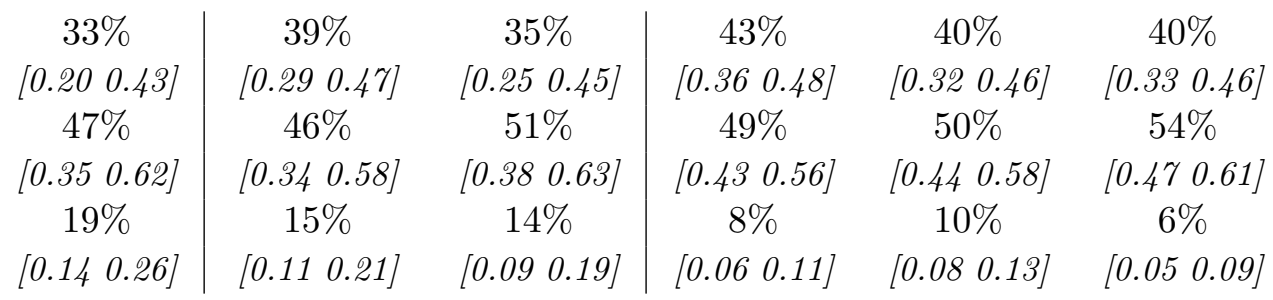

Note: GMM refers to the Olley-Pakes control function approach. Plant-level output prices refers to deflating revenue using product level prices indexes. Plant-level material prices refers to deflating material inputs costs using material specific price indexes. Bootstrapped 95\% confidence intervals using 10,000 replications shown in brackets, and these only include sampling error in the computation of productivity $\omega$. 
Figure 1: Evolution of the Steel Industry, and Vertically Integrated Mills and Minimills
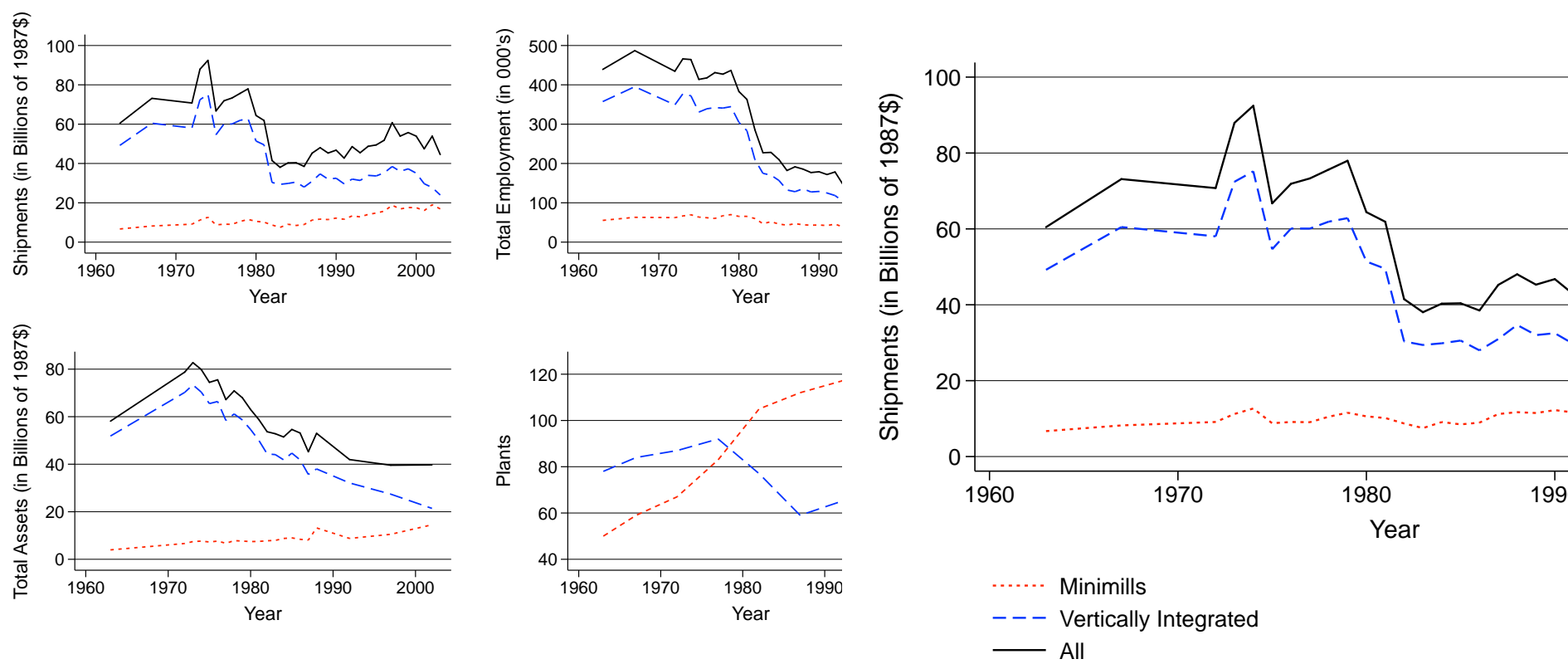

Fiøure 2: Minimills Market share bv Major Product.

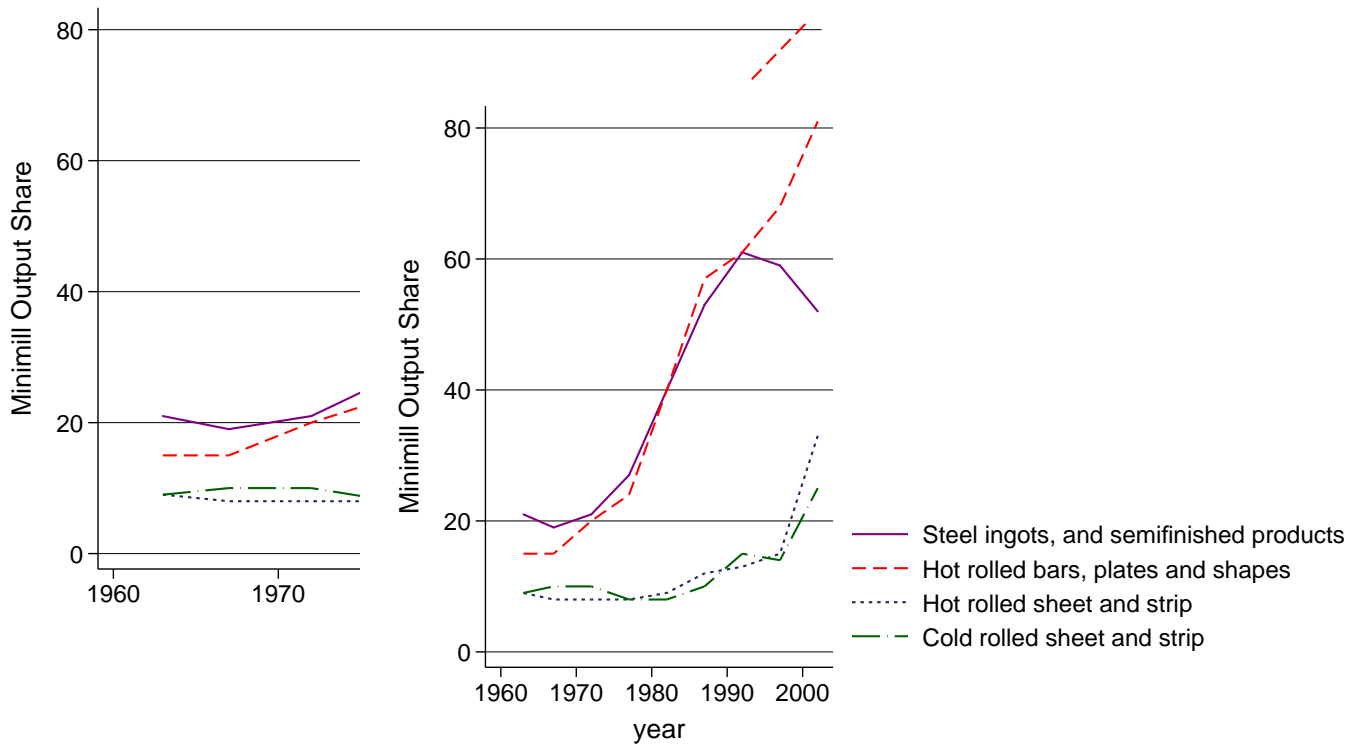


Figure 3: Producer Output Price Index by Product Segment

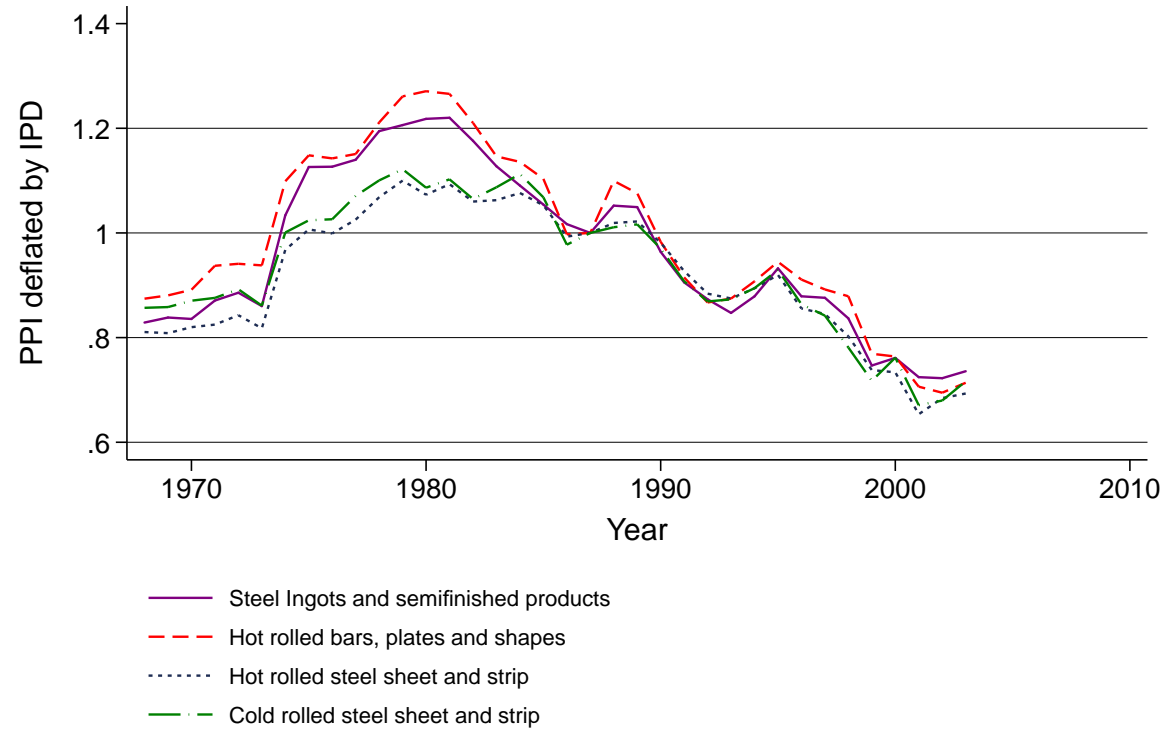

Note: Producer Price Index for Selected Steel Products deflated by GDP Deflator. Base year $1987=100$. Source: BLS.

Figure 4: Market Share Weighted Markups

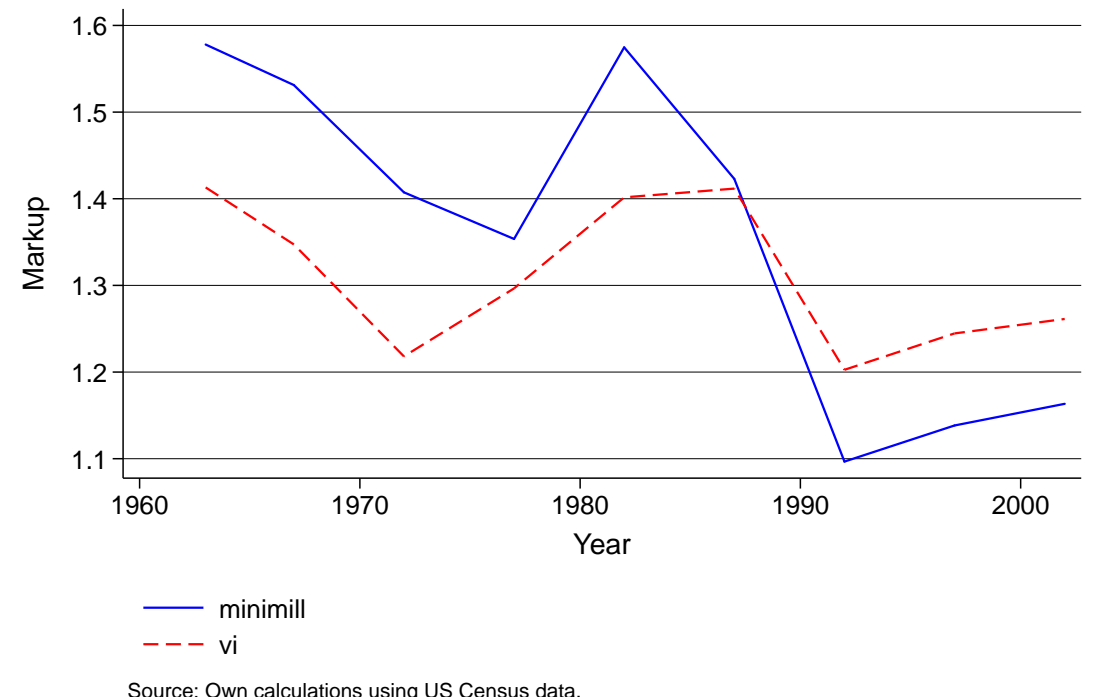




\section{A Data Appendix}

\section{A.1 Sample Selection}

We pull all plants in the Census of Manufacturing, Annual Survey of Manufacturing and Longitudinal Business Database from 1963 to 2007 coded in either NAICS 33111 or SIC 3312 at some point in their lives.

The Longitudinal Business Database has worse industry coding than the Census of Manufacturing, and taking its coding literally introduces a large number of non-steel mills into the sample ${ }^{30}$ Therefore, we include a plant in the sample only if it has been coded in steel in either the CMF or the ASM.

\section{A.2 Coding Minimills, Vertically Integrated, and Rolling Plants}

A primary issue in understanding the Steel industry is how to code plants as being minimills, vertically integrated or rolling and processing plants. For references on the differences between minimills and vertically integrated plants and the production process for steel, see Fruehan (1998) p.1-12 and Crandall (1981) p.5-15.

The 2007, 2002 and 1997 Census of Manufacturing have a special inquiry questionnaire for the steel industry (SI) appended to it. This questionnaire asks plants if they are considered a minimill or not. Moreover, the SI also asks for plant hours in electric arc furnaces, blast furnaces, coke ovens, and basic oxygen furnaces. If a plant reports plant hours in coke, blast, or basic oxygen furnace, we flag this plant as a vertically integrated plant, since vertically integrated plants are defined by the production process that first produces pig iron and slag, and then processes the result in a basic oxygen furnace. If a plant reports being a minimill or if it reports hours in an electric arc furnace, then we code this plant as a minimill.

Some vertically integrated plants occasionally have electric arc furnaces. Whenever a plant report hours in an electric arc furnace and in a basic oxygen or blast furnace, we assign this plant to the vertically integrated category. The reason is that the vertically integrated section of the plant is usually far bigger than the electric furnace section.

Many plants do not report hours in any steel mill department, and do not report being minimills either. We call these plants rolling mills or processors, as they do not produce steel per se, but process steel products. For instance, a rolling mill might use steel ingots, blooms and billets (steel shapes), and roll these into steel sheet. Alternatively, a mill might take steel rods and shape them into steel screws.

For plants that were still in operation in 1997, or were built after 1997, the SI file is all we need to identify the plant's type. However, for plants that shut down pre-1997, we use the material and product trailer to the Census of Manufacturing to classify them.

Minimills can be identified by their input use. Electric arc furnaces use a combination of scrap steel and direct-reduced iron as inputs. Thus, if a plant uses any direct-reduced iron, we flag this plant as a minimill. Likewise, if scrap steel represents more than 20 percent of a plant's material use, we flag this plant as a minimill 31

Vertically integrated plants can also be identified from their input use. If a plant uses "Coal for Coke", this is a good indication that a plant has a blast furnace. We flag rolling mills by their use of "Steel Shapes and Forms" - steel ingots and so on that are shaped into steel products.

\footnotetext{
${ }^{30}$ In particular, the Zip Business Patterns database, that uses the same underlying source as the LBD, has a large number of entrants coded in NAICS 33111 from 1997 to 2002 that are not steel mills.

${ }^{31}$ Basic oxygen furnaces at vertically integrated plants also can a take a small percent of scrap steel. For this reason, we flag a plant as a minimill only if scrap steel is a large part of their inputs.
} 
We also use the product trailer to categorize plants. If a plant produces "Coke Oven or Blast Furnace Products", we flag this plant as vertically integrated. In addition, if a plant produces "Cold Rolled Sheet Steel" before 1980, we flag this plant as vertically integrated, as minimills only started producing cold rolled sheets in the mid-80s. For references on the changing ability of minimills to produce sheet products, see Rogers (2009) on page 162 and chapter 8 of Hall (1997).

Plants are not always consistently coded as either minimills, vertically integrated, or rolling mills from one year to another. Thus, we classify a plant based on its history of such flags. Specifically, a plant is vertically integrated if it is flagged as such at least 80 percent of the time. Likewise, a plant is assigned to the minimill category if it is flagged as such at least 80 percent of the time.

Since vertically integrated plants, as their name suggests, are typically engaged in multiple activities, such as having an electric arc furnace and a basic oxygen furnace, along with a rolling mill, we first flag plants as vertically integrated or not, then flag the remaining plants as minimills. Leftover plants are assigned to be rolling mills.

\section{A.3 Coding Products}

We use the product trailer of the Census Bureau to investigate the products produced by steel producers. We categorize products into the following types which are responsible for 93 percent of output not categorized as "other" or "unclassified" in 1997: Hot-Rolled Steel Bar: SIC 33124, NAICS 3311117; Hot Rolled Sheet and Strip: SIC 33123, NAICS 3311115; Cold Rolled Sheet and Strip: SIC 33127, SIC 33167, NAICS 3312211, NAICS 3312211D; Cold Finished Bars and Bar Shapes: SIC 33128, SIC 33168, NAICS 3312213, NAICS 331111F; Steel Ingots and Semi-Finished Shapes: SIC 33122, NAICS 3311113; Steel Wire: SIC 33125, SIC 33155, NAICS 3312225, NAICS 3311119; Steel Pipe and Tube: SIC 33170, SIC 33177, NAICS 3312100, NAICS 331111B.

The tables below provide summary statistics of our sample, and contrast the minimill producers to the traditional vertical integrated producers. We also provide more details on the various products of the industry. 
Table A.1: Summary Statistics for Minimills and Vertically Integrated Producers Vertically Integrated

\begin{tabular}{lrrr}
\hline & Mean & Std. Dev. & Observations \\
Shipments $\dagger$ & 647 & 671 & 2,192 \\
Value Added $\dagger$ & 261 & 311 & 2,192 \\
Cost of Materials $\dagger$ & 343 & 369 & 2,192 \\
Investment $\dagger$ & 36 & 63 & 2,192 \\
Assets $\dagger$ & 690 & 860 & 1,525 \\
Workers & 3,062 & 3,721 & 2,192 \\
Wage Per Hour & 25 & 8 & 2,192 \\
& & & \\
Minimills & & & \\
& Mean & Std. Dev. & Observations \\
Shipments $\dagger$ & 153 & 178 & 2,687 \\
Value Added $\dagger$ & 61 & 80 & 2,687 \\
Cost of Materials $\dagger$ & 85 & 112 & 2,687 \\
Investment $\dagger$ & 7 & 17 & 2,687 \\
Assets $\dagger$ & 103 & 139 & 1,705 \\
Workers & 633 & 750 & 2,687 \\
Wage Per Hour & 25 & 9 & 2,687
\end{tabular}

Note: † In millions of 1997 dollars. The number of observations for total assets is smaller since these are not part of the ASM after 1992. 
Table A.2: Differences between Minimills and Vertically Integrated Plants Plant-level characteristic Premium for VI Plants

\begin{tabular}{|c|c|c|c|c|c|}
\hline & All 1963 & 1972 & 1982 & 1992 & 2002 \\
\hline Shipments & $\begin{array}{rr}1.44 & 1.60 \\
(0.08) & (0.27)\end{array}$ & $\begin{array}{r}1.60 \\
(0.25)\end{array}$ & $\begin{array}{r}1.46 \\
(0.23)\end{array}$ & $\begin{array}{r}1.32 \\
(0.23)\end{array}$ & $\begin{array}{r}1.02 \\
(0.26)\end{array}$ \\
\hline Value Added & $\begin{array}{rr}1.32 & 1.43 \\
(0.09) & (0.30)\end{array}$ & $\begin{array}{r}1.33 \\
(0.26)\end{array}$ & $\begin{array}{r}1.23 \\
(0.24)\end{array}$ & $\begin{array}{r}1.31 \\
(0.25)\end{array}$ & $\begin{array}{r}0.97 \\
(0.28)\end{array}$ \\
\hline Assets & $\begin{array}{rr}1.68 & 2.11 \\
(0.10) & (0.32)\end{array}$ & $\begin{array}{r}1.88 \\
(0.29)\end{array}$ & $\begin{array}{r}1.88 \\
(0.27)\end{array}$ & $\begin{array}{r}1.46 \\
(0.28)\end{array}$ & $\begin{array}{r}1.17 \\
(0.31)\end{array}$ \\
\hline Cost of Materials & $\begin{array}{rr}1.57 & 1.88 \\
(0.08) & (0.28)\end{array}$ & $\begin{array}{r}1.74 \\
(0.25)\end{array}$ & $\begin{array}{r}1.70 \\
(0.23)\end{array}$ & $\begin{array}{r}1.34 \\
(0.24)\end{array}$ & $\begin{array}{r}1.04 \\
(0.26)\end{array}$ \\
\hline Employment & $\begin{array}{rr}1.24 & 1.37 \\
(0.08) & (0.26)\end{array}$ & $\begin{array}{r}1.30 \\
(0.24)\end{array}$ & $\begin{array}{r}1.32 \\
(0.22)\end{array}$ & $\begin{array}{r}1.20 \\
(0.22)\end{array}$ & $\begin{array}{r}0.97 \\
(0.25)\end{array}$ \\
\hline Shipment per worker & $\begin{array}{rr}0.20 & 0.23 \\
(0.03) & (0.10)\end{array}$ & $\begin{array}{r}0.25 \\
(0.09)\end{array}$ & $\begin{array}{r}0.14 \\
(0.08)\end{array}$ & $\begin{array}{r}0.12 \\
(0.08)\end{array}$ & $\begin{array}{r}0.05 \\
(0.10)\end{array}$ \\
\hline Value Added per worker & $\begin{array}{rr}0.08 & 0.06 \\
(0.04) & (0.13)\end{array}$ & $\begin{array}{r}0.03 \\
(0.11)\end{array}$ & $\begin{array}{l}-0.09 \\
(0.10)\end{array}$ & $\begin{array}{r}0.12 \\
(0.11)\end{array}$ & $\begin{array}{r}0.00 \\
(0.12)\end{array}$ \\
\hline Wage & $\begin{array}{rr}0.06 & 0.04 \\
(0.01) & (0.05)\end{array}$ & $\begin{array}{r}0.07 \\
(0.04)\end{array}$ & $\begin{array}{r}0.14 \\
(0.04)\end{array}$ & $\begin{array}{r}0.00 \\
(0.04)\end{array}$ & $\begin{array}{r}0.07 \\
0.04)\end{array}$ \\
\hline
\end{tabular}

Note: Estimates display the log of the ratio of the mean for VI plants over the mean for MM plants. Thus, 1.44 in the top left cell indicates that the average vertically integrated plant shipped 144 percent more than the average minimill or, equivalently, 4.2 times more, while a coefficient of 0 indicates that VI and MM plants have identical means. Year Controls included in each regression. There are a total of 1499 observations in these regressions. 
Table A.3: Production by Product

\begin{tabular}{crrrrrrrrr} 
Year & HRS & HRB & CRS & Ingots & P\&T & Blast & CFB & Wire & Other \\
\hline 1963 & 23 & 23 & 16 & 13 & 7 & 5 & 1 & 2 & 9 \\
1967 & 21 & 23 & 14 & 13 & 7 & 5 & 1 & 2 & 14 \\
1972 & 27 & 23 & 16 & 10 & 6 & 5 & 1 & 2 & 9 \\
1977 & 26 & 22 & 17 & 10 & 8 & 7 & 1 & 1 & 8 \\
1982 & 30 & 21 & 15 & 8 & 11 & 5 & 1 & 1 & 9 \\
1987 & 38 & 20 & 17 & 8 & 5 & 3 & 1 & 1 & 7 \\
1992 & 37 & 21 & 16 & 8 & 5 & 4 & 2 & 1 & 7 \\
1997 & 35 & 21 & 17 & 7 & 6 & 4 & 2 & 1 & 7 \\
2002 & 31 & 22 & 23 & 7 & 6 & 2 & 2 & 2 & 6
\end{tabular}

Note: Fraction of Industry Output Accounted for by each product: Hot-rolled steel sheet (HRS), Hot-rolled bar (HRB), Cold-rolled sheet (CRS), Ingots and shapes, Pipe and tube (P \& T), Wire, Cold-finished bars (CFB), and coke oven and blast furnace products (Blast), Steel Wire (Wire). The one product whose shipments fall notably over this period is steel ingots and semi-finished shapes (SISS). However, SISS are used primarily in rolling mills to produce steel sheet and bar. Since the mid 1990's with the development of slab casting technologies, steel has been directly shaped into sheets at the mill. 


\section{B Output and Input Deflators}

Recovering productivity using revenue and expenditure data requires that we correct for potential price variation across plants and time, for both output and inputs. Below, we describe our procedure.

\section{B.1 Output price deflator}

In order to guarantee that we recover productivity, $\omega_{i t}$, using plant/product revenue data we rely on a plant-specific output deflator. We construct this deflator using product-level revenues at the plant level (recorded in the census data) in combination with product-level price data (from the BLS) 32

To make sure that price variation - across plants and time - is fully controlled for, we assume the following structure: Plants charge the same markup across all their products, while markups can flexibly vary across plants and time. The heterogeneity in markups will naturally arise if plants are heterogeneous in their underlying productivity.

Before we derive the exact price deflator, we state explicitly what we observe in the data: revenues $\left(R_{i j t}\right)$, input $\left(X_{i t}\right)$ and prices $\left(P_{j t}\right)$.

We start out with the following production function:

$$
Q_{i j t}=X_{i j t} \Omega_{i t}
$$

where we are explicit about productivity only being plant-specific and not plant-product-specific. The input bundle $X_{i j t}$ contains labor, intermediate inputs and capital, scaled by their corresponding technology parameters, $X=L^{\beta_{l}} K^{\beta_{k}} M^{\beta_{m}}$.

Now consider plant-level revenue, which is obtained by summing product-specific revenues, and using the production function:

$$
R_{i t}=\sum_{j} X_{i j t} \Omega_{i t} P_{j t}
$$

To recover plant-level productivity from a regression of plant-level (deflated) revenues and input use, we use:

$$
X_{i j t} \equiv s_{i j t} X_{i t}
$$

Plugging the last expression into the one for plant-level revenue, we get:

$$
R_{i t}=\Omega_{i t} X_{i t} \sum_{j} s_{i j t} P_{j t}
$$

Up to $s_{i j t}$, which we will discuss below, everything is directly observable and, therefore, we can recover productivity using standard estimation techniques using:

$$
\frac{R_{i t}}{\sum_{j} s_{i j t} P_{j t}}=X_{i t} \Omega_{i t}
$$

or in logs:

\footnotetext{
${ }^{32}$ Specifically, we use the following BLS price series: PCU331111331111: Steel; PCU3311113311111: Coke oven and blast furnace products; PCU3311113311113: Steel ingots and semifinished products; PCU3311113311115: Hot rolled steel sheet and strip; PCU3311113311117: Hot rolled steel bars, plates, and structural shapes; PCU3311113311119: Steel wire; PCU331111331111B: Steel pipe and tube; PCU331111331111D: Cold rolled steel sheet and strip and PCU331111331111F: Cold finished steel bars.
} 


$$
r_{i t}-\tilde{p}_{i t}=\beta_{l} l_{i t}+\beta_{k} k_{i t}+\beta_{m} m_{i t}+\omega_{i t}+\epsilon_{i t}
$$

where $\tilde{p}_{i t} \equiv \sum_{j} s_{i j t} P_{j t}$ is the plant-level output price deflator, and we use that the (log) input bundle can be decomposed into labor and capital input, scaled by their corresponding output elasticity $\beta$. The additional error term $\epsilon_{i t}$ captures measurement error in either revenue or prices, as well as unanticipated shocks to output.

In order to take equation (B.6) to the data, we need to take a stand on the input allocation or what $s_{i j t}$ is. We use revenue shares:

$$
s_{i j t}=\frac{R_{i j t}}{\sum_{j} R_{i j t}},
$$

which we can directly compute in our data. The use of revenue shares restricts the markups to be the same across the products of a, potentially, multi-product plant. To see this it is useful to use the framework of De Loecker and Warzynski (2012) to recover markups and apply it to our setting. The markup $\mu_{i j t}$ is obtained using the FOC on input $X$ of cost minimization:

$$
\mu_{i j t}=\beta^{X} \frac{R_{i j t}}{P_{i t}^{X} s_{i j t} X_{i t}} .
$$

Now, using equation (B.7), we get the following expression for markups:

$$
\mu_{i j t}=\beta^{X} \frac{R_{i t}}{P_{i t}^{X} X_{i t}}
$$

which highlights that $\mu_{i j t}=\mu_{i t}$ and $\forall j \in J_{i}$, with $J_{i}$ the set of products produced by $i$.

Note that the reason we need to restrict markups across products within a plant to be constant, is because we see aggregate input use only at the plant level ${ }^{33}$ Finally, although we directly observe revenues for all product-plant combinations, we only observe product specific prices and assume away the variation across plants for a given product. In our empirical analysis, we rely on both the aggregate price index and our constructed plant-specific price index.

\section{B.2 Input price deflator}

The construction of the input price deflator is very similar to that of the output price deflator. There are, however, a few important differences. First, we need to distinguish between our three main input categories: labor, intermediate inputs and capital. Second, for some of the inputs, we observe plant-level input prices, that we can directly use to construct the deflator.

\section{B.2.1 Labor and capital}

We directly observe hours worked at the plant-level. We rely on the NBER capital deflator to correct the capital stock series. The use of an aggregate deflator implies that we assume a common user cost of capital across plants.

\section{B.2.2 Intermediate inputs}

The data on intermediate input use is potentially the most contaminated by input price variation, both in the cross-section and in the time series and, in particular, across the two types: VI and

\footnotetext{
${ }^{33}$ See De Loecker and Warzynski (2012) and De Loecker, Goldberg, Khandelwal, and Pavcnik (2012) for a detailed discussion of the input allocation across products.
} 
MM. As discussed in the main text, both technologies use vastly different intermediate inputs or use inputs at very different intensities. Note that the share of all intermediate inputs is not significantly different across types, but this masks the underlying heterogeneity. Due to the very different input use, we are concerned that the aggregate deflator does not fully capture the input price differences across plants and time.

We construct a plant-level intermediate input price deflator in the following way. We consider $n$ intermediate inputs where $n=\{$ Fuel $(\mathrm{F})$, Electricity $(\mathrm{E})$, Coal for coke $(\mathrm{C})$, iron ore $(\mathrm{I})$, iron and scrap $(\mathrm{S})$, Others $(\mathrm{O})\}$. In the data we observe expenditures by intermediate input $\left(M_{i n t}^{E}\right)$ and prices for each input $n\left(P_{i t}^{n}\right)$.

The plant-level intermediate input price deflator is constructed as follows:

$$
\begin{array}{r}
P_{i t}^{M}=\sum_{n} s_{i t}^{n} P_{t}^{n} \\
s_{i t}^{n}=\frac{M_{i n t}^{E}}{\sum_{n} M_{i t}^{E}} \\
P_{t}^{n}=N^{-1} \sum_{i} P_{i t}^{n} .
\end{array}
$$

In words, we compute the average price for a given input $n, P_{t}^{n}$, and weigh this by the plant's input share $s_{i t}^{n}$. This structure still assumes a common input price for all plants for a given input $n$, but it recognizes that the intensity can vary across plants. In practice we compute $(\mathrm{B} .12)$ for all but the Fuel and Others categories. For those two, we directly rely on the NBER Fuel Price Deflator and the aggregate input price deflator, respectively. The other categories are a combination of various inputs for which we do not observe reliable input price data and, therefore, we decided to rely on the aggregate input price deflator. In terms of the log specification of the production function $m_{i t}=\ln \left(\sum_{n} \frac{M_{i n t}^{E}}{P_{i t}^{M}}\right)$.

We plot our input price deflator, averaged by technology type, below and compare it to the publicly available input price deflator - i.e., the NBER Material Price Index.

\section{Measuring Productivity and Markups}

We briefly discuss how we estimate productivity and recover markups using our plant-level panel on production and prices. This discussion will follow the exposition of control function estimation of productivity in Ackerberg, Frazer, and Caves (2006).

\section{C.1 Productivity}

We take equation (4) to the data and follow the standard in the literature, relying on a plant's optimal investment equation to control for unobserved productivity shocks. See De Loecker and Warzynski (2012) for more details.

Specifically, the first stage of this procedure runs output $\tilde{q}_{i t}$ on a flexible function of inputs $\left(l_{i t}, m_{i t}, k_{i t}\right)$, an investment control function $i_{i t}$, as well as year-plant type controls. In other words:

$$
\tilde{q}_{i t}=\phi_{\psi, t}\left(l_{i t}, m_{i t}, k_{i t}, i_{i t}\right)+\epsilon_{i t} .
$$

And productivity is recovered as $\omega_{i t}=\hat{\phi}_{i t}-f_{\psi, t}\left(L_{i t}, M_{i t}, K_{i t} ; \boldsymbol{\beta}\right)$. A key component in the estimation routine is the law of motion on productivity. In our baseline results, we stick to an 
Figure B.1: Producer Input Price Index

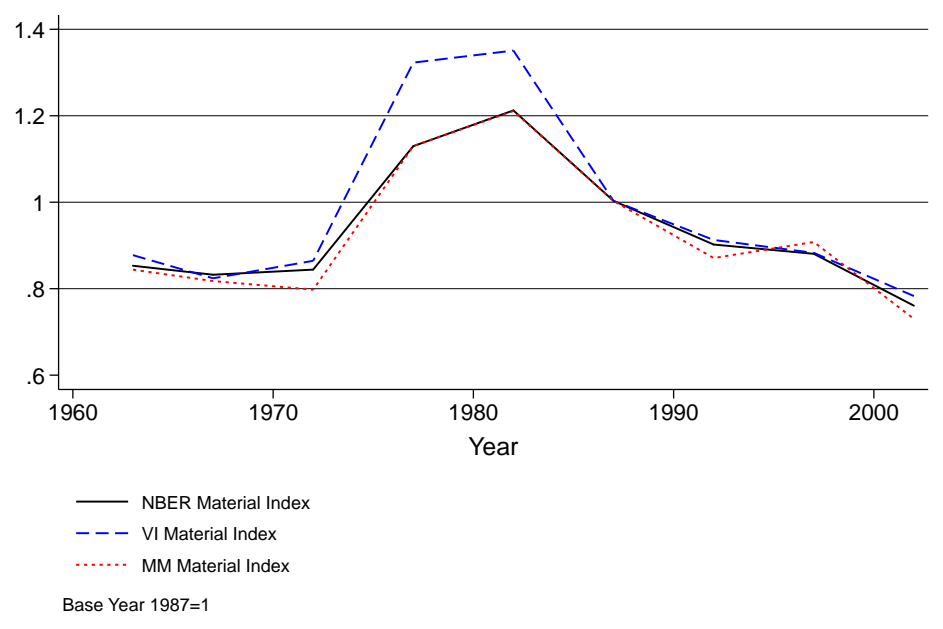

Note: Material Price Index deflated by GDP Deflator. Base year 1987=100.

exogenous Markov process given by

$$
\omega_{i t}=g_{\psi}\left(\omega_{i t-1}, \hat{\chi}_{i t}\right)+\xi_{i t}
$$

Note that this evolution is allowed to vary for minimills and vertically integrated plants, as we have seen in the OLS regressions that vertically integrated plants slowly catch up to minimills. Moreover, we control for the selection effect due to the fact that we only observed productivity conditionally on a plant remaining in the industry using the estimated propensity score of exiting $\hat{\chi}_{i t}$. To the extent that vertically integrated plants are larger and thus, at an ex-ante level more likely to remain in the industry, this will generate differential selection rules for minimills and vertically integrated plants.

We recover estimates of the production function coefficients, $\boldsymbol{\beta}$, by forming moments on this productivity shock $\xi_{i t}$. The identification of these coefficients relies on the rate at which inputs adjust to these shocks. In particular, we allow both labor and capital to be dynamically chosen inputs, whereby current values of capital (labor) do not react to current shocks to productivity $\left(\xi_{i t}\right)$. Plants do, however, adjust their intermediate input use (scrap, energy, other material inputs) to the arrival of a productivity shock $\xi_{i t}$.

The exact moments will depend on the functional form we select for $f($.$) . For our main speci-$ fications, we rely on Cobb-Douglas production functions and use the following moments:

$$
E\left(\xi_{i t}(\boldsymbol{\beta})\left(\begin{array}{c}
l_{i t} \\
m_{i t-1} \\
k_{i t}
\end{array}\right)\right)=0 .
$$

A recent literature (Ackerberg, Frazer, and Caves, 2006) has pointed out that the identification of the variable input, the coefficient of $\beta_{m}$ in our case, relies on sufficient variation in plant-level input prices. The coefficient on labor (capital) is identified using variation in adjustment cost and relies on the fact that plants cannot immediately adjust their labor (capital) use to a productivity shock. All our results are invariant to modifications of the timing assumptions discussed in the 
main text. Our approach is flexible and can allow for a variety of production functions combined with various assumptions on the variability of inputs, as well as the use of alternative proxies such as intermediate inputs.

\section{C.2 Estimating Markups}

Our approach to recovering markups follows De Loecker and Warzynski (2012). In the rest of this section, we briefly review the approach. In addition to the production function we introduced before, we only have to assume that producers active in the market minimize costs. Let $\mathbf{V}_{i t}$ denote the vector of variable inputs used by the firm. We use the vector $\mathbf{K}_{i t}$ to denote dynamic inputs of production. Any input that faces adjustment costs will fall into this category; capital is an obvious one, but our framework allows us to also include labor.

The associated Lagrangian function is:

$$
\mathcal{L}\left(V_{i t}^{1}, \ldots, V_{i t}^{V}, \mathbf{K}_{i t}, \lambda_{i t}\right)=\sum_{v=1}^{V} P_{i t}^{v} V_{i t}^{v}+\mathbf{r}_{i t} \mathbf{K}_{i t}+\lambda_{i t}\left(Q_{i t}-Q_{i t}\left(V_{i t}^{1}, \ldots, V_{i t}^{V}, \mathbf{K}_{i t}, \omega_{i t}\right)\right)
$$

where $P_{i t}^{v}$ and $\mathbf{r}_{i t}$ denote a firm's input prices for a variable input $v$ and dynamic inputs, respectively. The first-order condition for any variable input free of adjustment costs is

$$
\frac{\partial \mathcal{L}_{f t}}{\partial V_{i t}^{v}}=P_{i t}^{v}-\lambda_{i t} \frac{\partial Q_{i t}(.)}{\partial V_{i t}^{v}}=0 .
$$

where the marginal cost of production at a given level of output is $\lambda_{i t}$, as $\frac{\partial \mathcal{L}_{i t}}{\partial Q_{i t}}=\lambda_{i t}$. Rearranging terms and multiplying both sides by $\frac{V_{i t}}{Q_{i t}}$, generates the following expression.

$$
\frac{\partial Q_{i t}(.)}{\partial V_{i t}^{v}} \frac{V_{i t}^{v}}{Q_{i t}}=\frac{1}{\lambda_{i t}} \frac{P_{i t}^{v} V_{i t}^{v}}{Q_{i t}}
$$

Cost minimization implies that optimal input demand is realized when a firm equalizes the output elasticity of any variable input $V_{i t}^{v}$ to $\frac{1}{\lambda_{i t}} \frac{P_{i t}^{v} V_{i t}}{Q_{i t}}$.

Define markup $\mu_{i t}$ as $\mu_{i t} \equiv \frac{P_{i t}}{\lambda_{i t}}$. As De Loecker and Warzynski (2012) show, the costminimization condition can be rearranged to write markup as:

$$
\mu_{i t}=\theta_{i t}^{v}\left(\alpha_{i t}^{v}\right)^{-1}
$$

where $\theta_{i t}^{v}$ denotes the output elasticity on an input $V^{v}$ and $\alpha_{i t}^{v}$ is the revenue share of variable input

$v$, defined by $\frac{P_{i t}^{v} V_{i t}^{v}}{P_{i t} Q_{i t}}$, which is data. This expression will form the basis for our approach: We obtain the output elasticity from the estimation of a production function and only need to measure the share of an input's expenditure in total sales. In particular, in our setting, $\theta_{i t}^{v}=\beta_{m}$.

In our context, the output elasticities are obtained by relying on product-specific price deflators, and potentially leave plant-level price variation left uncontrolled for. The latter is expected to bias the output elasticity downward and, therefore, downward-bias the level of the markup. Under a Cobb-Douglas production technology, this has no implications for the time-series pattern of markups and on the comparison of markups across minimills and integrated producers - as long as the output elasticity is fixed across types. 


\section{Deriving decompositions}

We provide more details on how we derive the various decompositions introduced in the main text. We start with the standard aggregate productivity definition:

$$
\Omega_{t}=\sum_{i} s_{i t} \omega_{i t}
$$

where we define:

$$
\begin{aligned}
s_{i t} & =\frac{R_{i t}}{\sum_{i} R_{i t}} \\
R_{t} & =\sum_{i} R_{i t}
\end{aligned}
$$

and $R_{i t}$ is plant-level total sales.

\section{D.1 Standard OP}

Olley and Pakes show that (D.1) can be written as:

$$
\begin{aligned}
\Omega_{i t} & =\bar{\omega}_{t}+\sum_{i}\left(s_{i t}-\bar{s}_{t}\right)\left(\omega_{i t}-\bar{\omega}_{t}\right) \\
& =\bar{\omega}_{t}+\Gamma_{t}^{O P}
\end{aligned}
$$

with $N_{t}$ the number of active plants at time $t$ and:

$$
\begin{aligned}
\bar{\omega}_{t} & =N^{-1} \sum_{i} \omega_{i t} \\
\bar{s}_{t} & =N^{-1} \sum_{i} s_{i t}
\end{aligned}
$$

\section{D.2 Deriving the Between covariance}

We show that aggregate productivity can be decomposed in a between technology covariance component and an average type-specific productivity component, which in itself is decomposed into type-specific within and covariance terms.

Start from (D.1) and simply break up the sum into the two technology types, i.e. $\psi=$ $\{M M, V I\}$ :

$$
\begin{aligned}
\Omega_{t} & =\sum_{i \in \psi=M M} s_{i t} \omega_{i t}+\sum_{i \in \psi=V I} s_{i t} \omega_{i t} \\
& =s_{t}(\psi=M M) \sum_{i \in \psi=M M} \frac{s_{i t}}{s_{t}(\psi=M M)} \omega_{i t} \\
& +s_{t}(\psi=V I) \sum_{i \in \psi=V I} \frac{s_{i t}}{s_{t}(\psi=V I)} \omega_{i t}
\end{aligned}
$$


The second line multiplies and divides each term by the relevant total market share of the type in the industry, i.e. $s_{t}(\psi)=\sum_{i \in \psi} s_{i t}{ }^{34}$

The last equation can now be rewritten as another weighted sum where we now sum over two groups: minimills and intergrated producers:

$$
\Omega_{t}=\sum_{\psi} s_{t}(\psi) \Omega_{t}(\psi)
$$

where

$$
\Omega_{t}(\psi)=\sum_{i \in \psi} \frac{s_{i t}}{s_{t}(\psi)} \omega_{i t}=\sum_{i \in \psi)} s_{i t}(\psi) \omega_{i t}
$$

The second line uses that the market share of a plant in the total industry divided by the total type-specific market share is equal to the plant's market share in the type's total sales $\left(s_{i t}(\psi)\right)$. Formally:

$$
s_{i t}(\psi)=\frac{s_{i t}}{s_{t}(\psi)}
$$

After having transformed the aggregate productivity expression into (D.8), we can rely on the same insight as $\mathrm{OP}$ and decompose aggregate productivity into a unweighted average and a covariance component. By transforming the expression using type-specific market shares we guarantee that the plant market shares sum to one; a necessary condition for the OP decomposition.

Applying the OP decomposition idea to (D.8) gives us:

$$
\begin{aligned}
\Omega_{t} & =\bar{\Omega}_{t}(\psi)+\sum_{\psi}\left(s_{t}(\psi)-0.5\right)\left(\Omega_{t}(\psi)-\bar{\Omega}_{t}(\psi)\right) \\
& =\bar{\Omega}_{t}(\psi)+\Gamma_{t}^{B}
\end{aligned}
$$

\section{D.3 Within type decompositions}

Starting from equation (D.11) we simply apply the OP decomposition by type $\psi$ and use the fact that we only have two technology types to obtain an expression for the average component:

$$
\begin{aligned}
\bar{\Omega}_{t}(\psi) & =\frac{1}{2} \sum_{\psi}\left(\Omega_{t}(\psi)\right) \\
& =\frac{1}{2} \sum_{\psi}\left(\bar{\omega}_{t}(\psi)+\sum_{i \in \psi}\left(s_{i t}(\psi)-\bar{s}_{t}(\psi)\right)\left(\omega_{i t}-\bar{\omega}_{t}(\psi)\right)\right) \\
& =\frac{1}{2} \sum_{\psi}\left(\bar{\omega}_{t}(\psi)+\Gamma_{t}^{O P}(\psi)\right)
\end{aligned}
$$

where we denote the average market share across a given type by $\bar{s}_{t}(\psi)=N_{\psi}^{-1} \sum_{i \in \psi} s_{i t}(\psi)$.

\footnotetext{
${ }^{34}$ The OP-decomposition relies crucially on the property that the market shares sum to one. However, if we were to simply split the summation across the two types, we could not isolate the within covariance term. To see this, note that $\sum_{\psi} \Omega_{t}(\psi) \neq \Omega_{t}$, due to the fact that $\sum_{\psi, i} s_{i t}(\psi)>1$.
} 


\section{D.4 Total decomposition}

To arrive at the expressions used in the main text we introduce $\Gamma_{t}(\psi)$ to denote a covariance of a given type and use superscripts $B$ and $O P$ to indicate whether the covariance is between or within the type, respectively. This gives us the following total decomposition of aggregate productivity:

$$
\Omega_{t}=\frac{1}{2} \sum_{\psi}\left[\bar{\omega}_{t}(\psi)+\Gamma_{t}^{O P}(\psi)\right]+\Gamma_{t}^{B}(\psi)
$$

If there was no entry or exit we can then directly evaluate the share of each component by tracking $\Omega_{t}$ over time. We incorporate the turnover process by relying on dynamic decompositions within a given type and can always scale the various subcomponents back to the decomposition discussed above. 